\title{
Estudio del impacto de las campañas de telemercadeo en el sector bancario de Colombia.
}


Impacto de las campañas de Tele mercadeo de ventas en las organizaciones del sector bancario.

NICOLAS MURCIA PATIÑO

SERGIO ANDRES PARRA CAICEDO

Tutor: Miller Rivera Lozano

BOGOTÁ D.C.

UNIVERSIDAD SANTO TOMAS DE COLOMBIA

FACULTAD ADMINISTRACIÓN DE EMPRESAS

2017 
Estudio del impacto de las campañas de telemercadeo en el sector bancario de Colombia.

NICOLÁS MURCIA PATIÑNO

SERGIO ANDRES PARRA CAICEDO

BOGOTÁ D.C.

UNIVERSIDAD SANTO TOMAS DE COLOMBIA

FACULTAD ADMINISTRACIÓN DE EMPRESAS

2017 


\section{CONTENIDO}

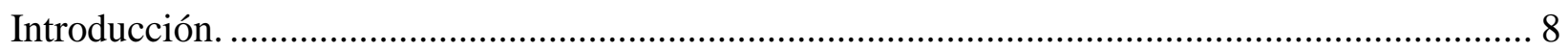

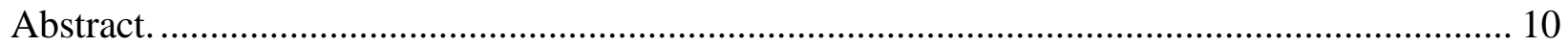

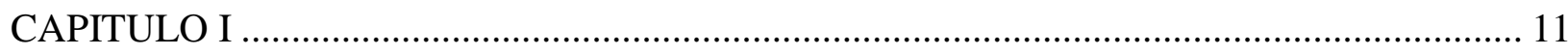

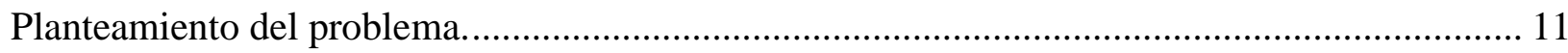

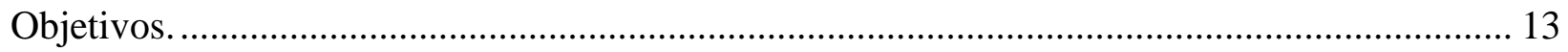

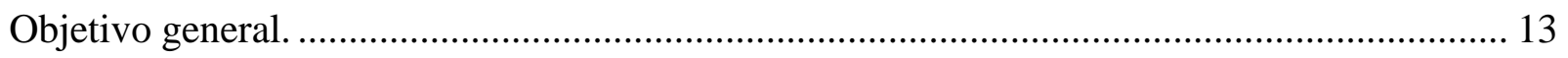

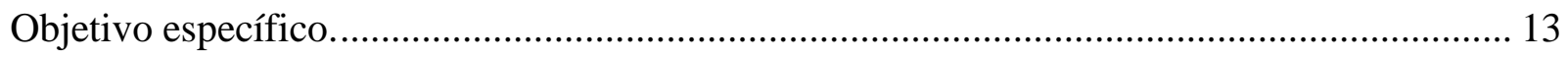

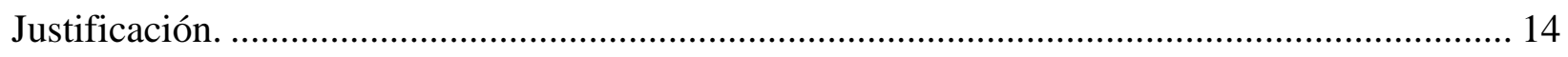

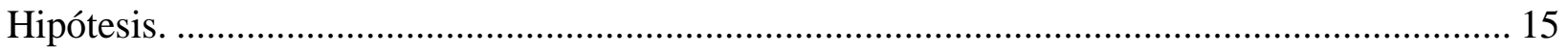

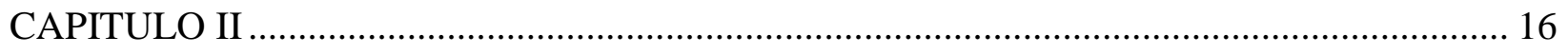

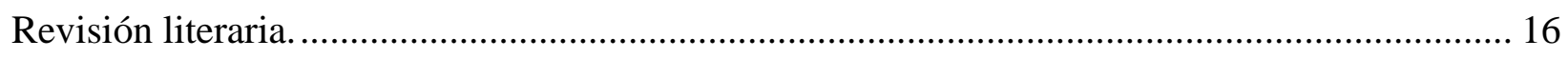

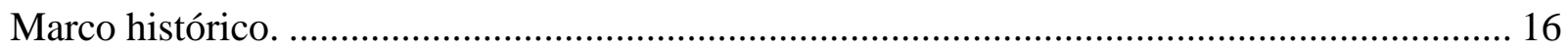

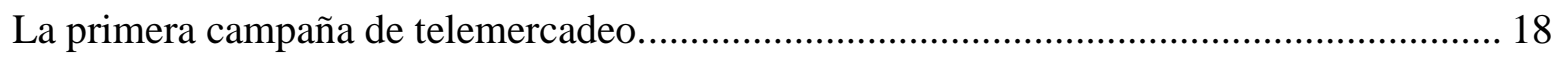

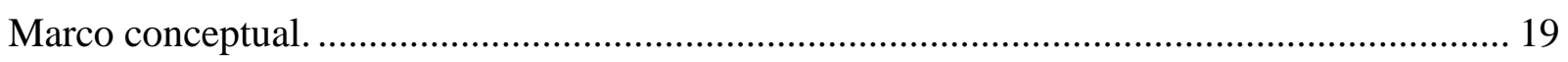

Diversos significados de las campañas de telemercadeo........................................................ 19

Enfoque principal de las campañas de telemercadeo.............................................................. 20

Instituciones financieras, comprendidas en sector bancario bajo un modelo de telemercadeo.

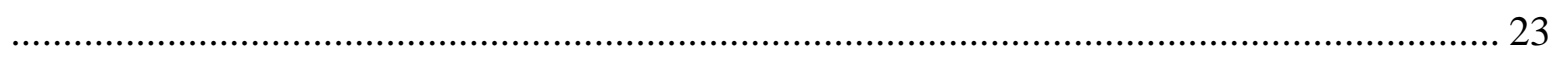

Definiciones comunes de las Campañas de Telemercadeo.................................................... 24

Glosario de términos utilizados en campañas de telemercadeo............................................ 25 


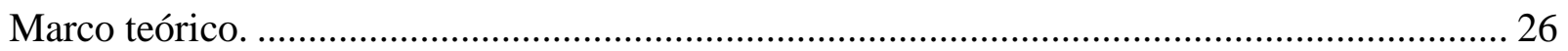

Evolución de las campañas de telemercadeo en Colombia....................................................... 27

El telemercadeo empleado desde diversas herramientas de comunicación. ............................... 27

Uso de las campañas de telemercadeo en el sector bancario ............................................. 28

Nuevas tecnologías mayores facilidades.............................................................................. 28

Crecimiento del mercado de las telecomunicaciones en Colombia ........................................... 29

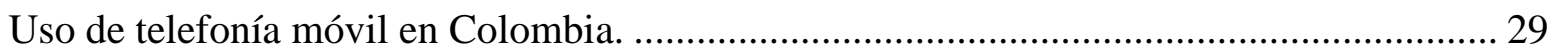

Impacto de las campañas de Tele mercadeo en la sociedad. ................................................. 32

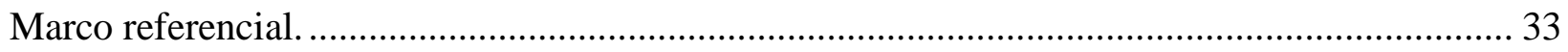

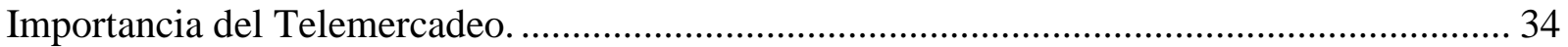

Usos del telemercadeo.................................................................................................. 34

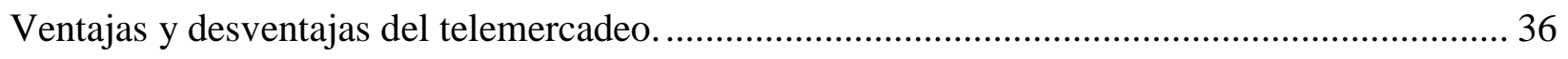

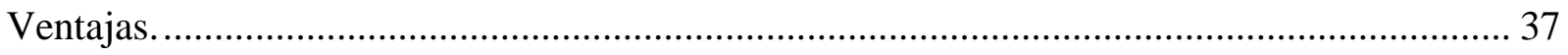

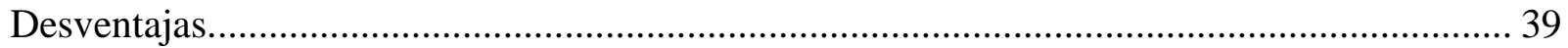

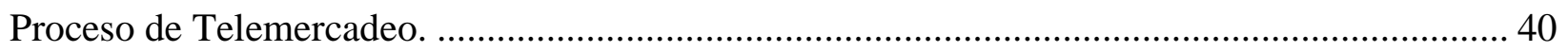

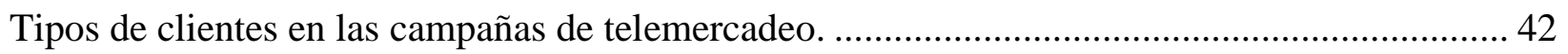

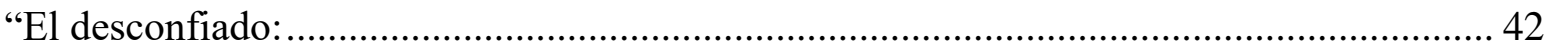

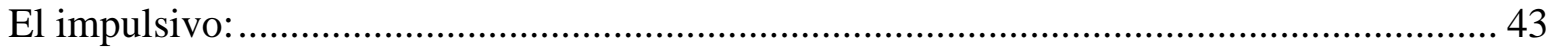

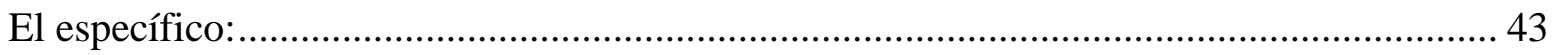

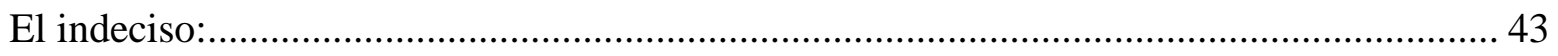

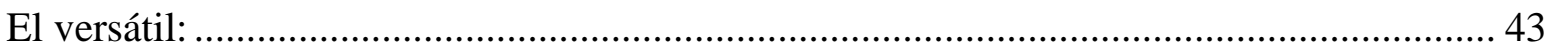

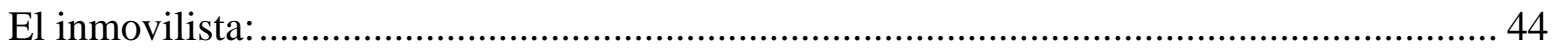

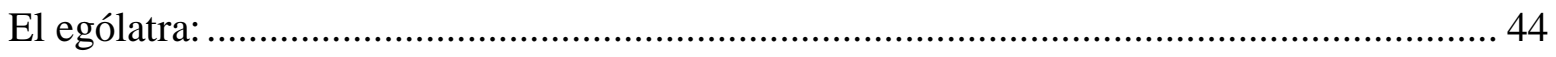

Estructura básica de un guion de telemercadeo. .............................................................................. 44 


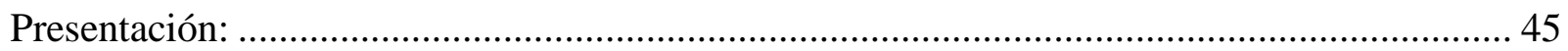

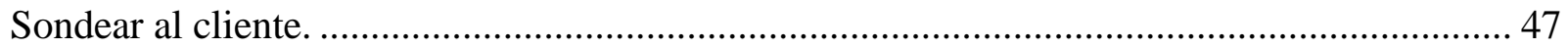

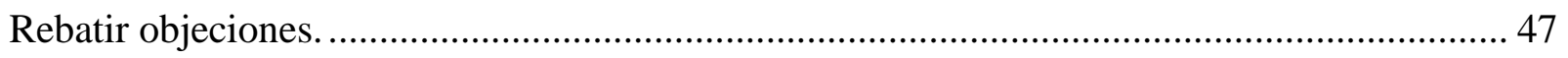

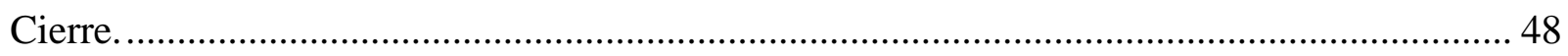

Segmentación de bases de datos en CRM................................................................................ 49

Tipo de información general que se debe indexar en la base de datos...................................... 50

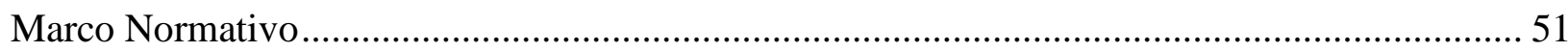

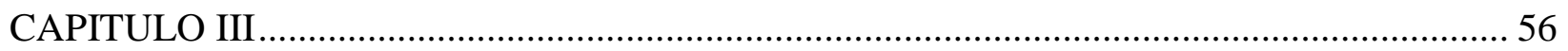

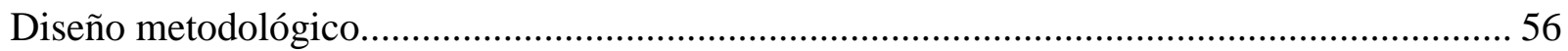

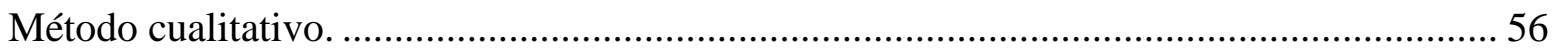

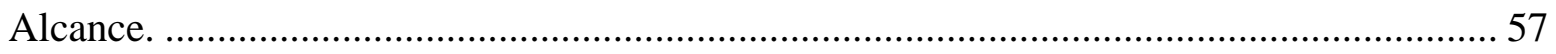

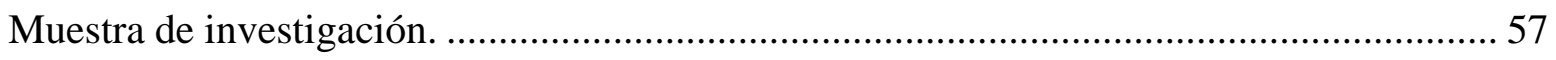

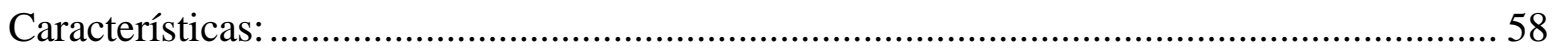

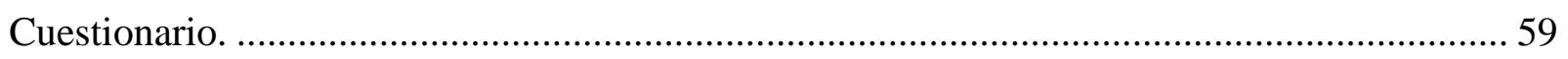

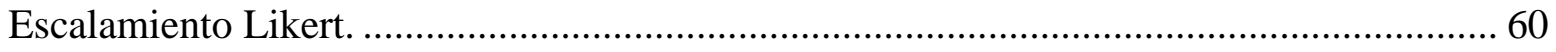

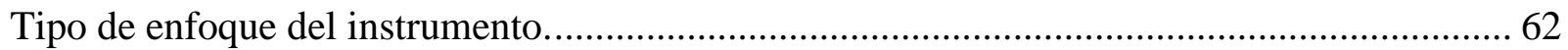

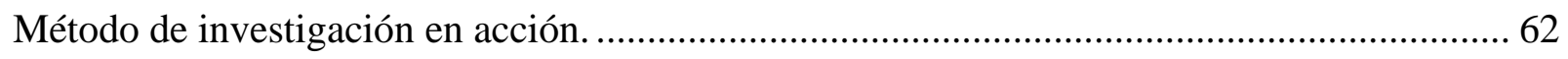

Figura 1 Principales acciones para llevar a cabo la investigación-acción. ............................. 63

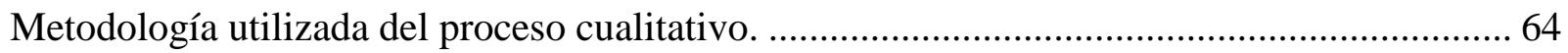

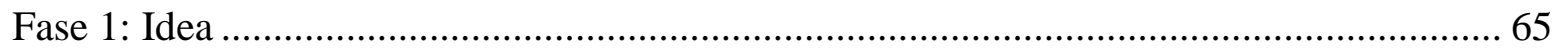

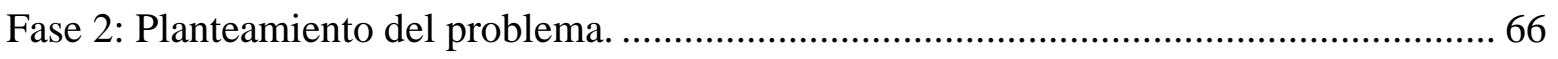

Fase 3: Revisión de la literatura y desarrollo del marco teórico................................................ 66

Fase 4: visualización del alcance del estudio....................................................................... 66

Fase 5: Elaboración de hipótesis y definición de las variables................................................ 66

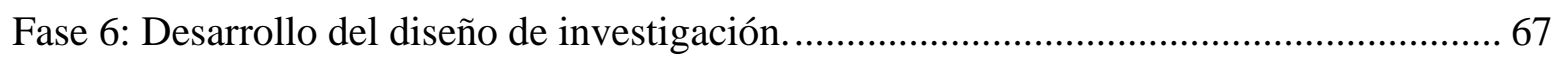




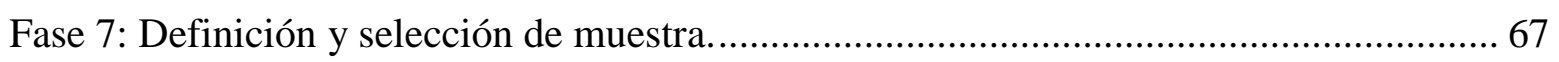

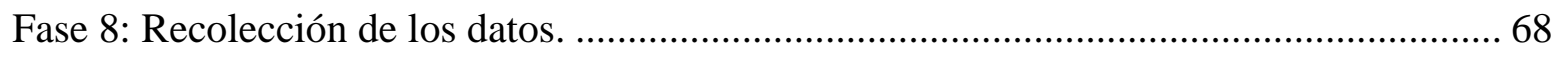

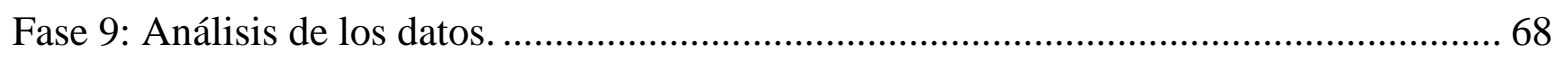

Fase 10: Elaboración del reporte de resultados.......................................................... 68

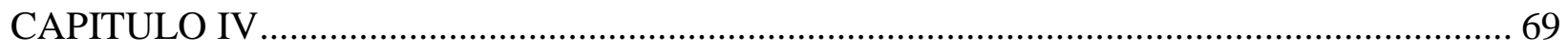

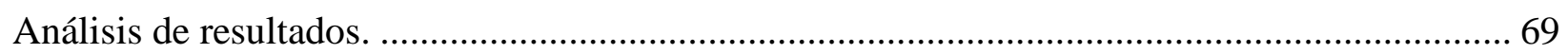

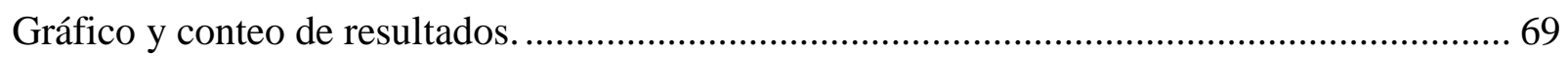

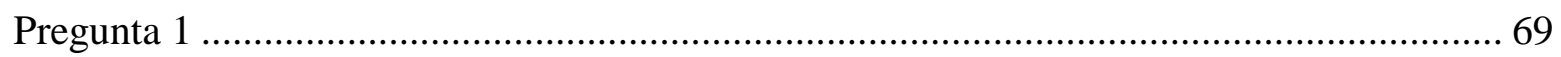

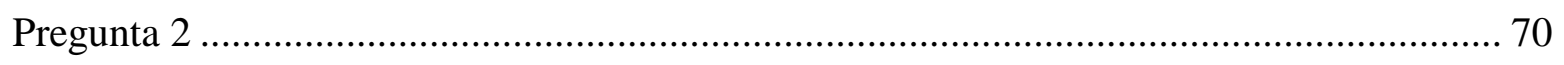

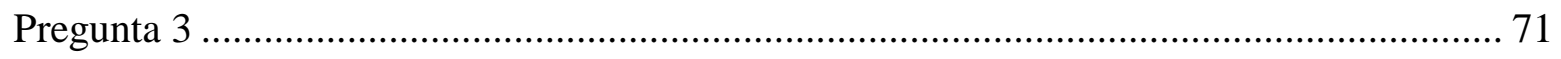

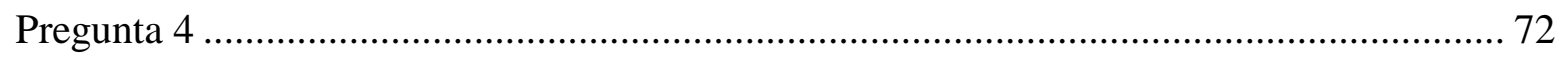

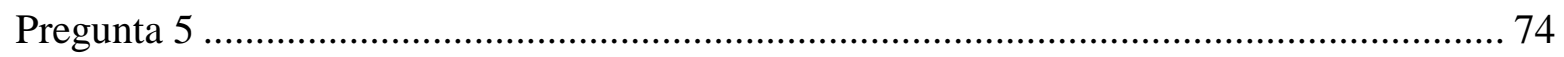

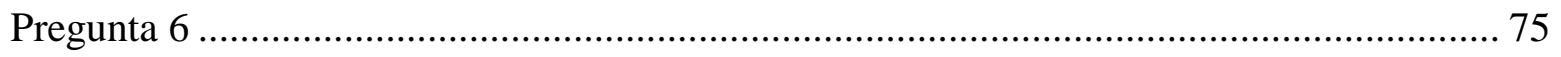

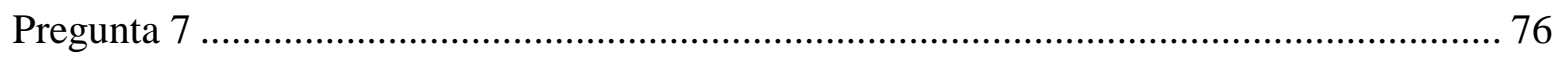

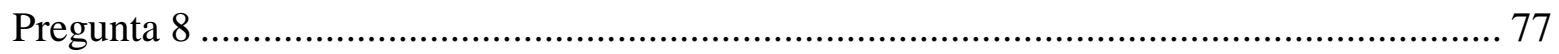

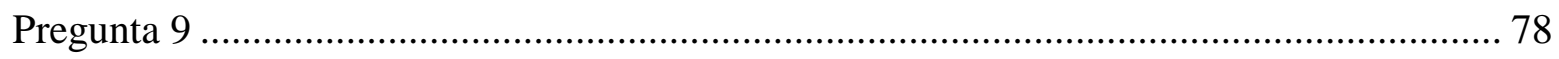

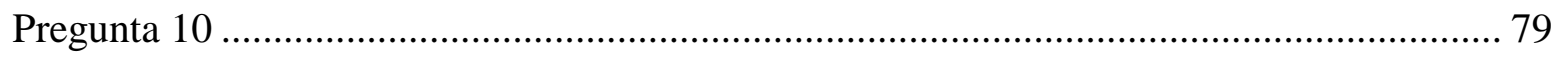

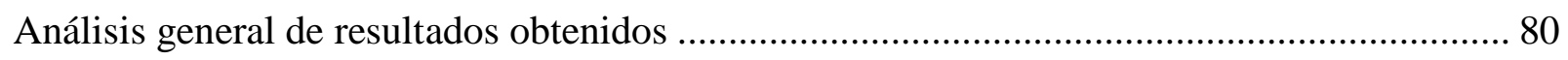

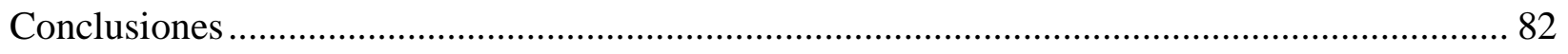

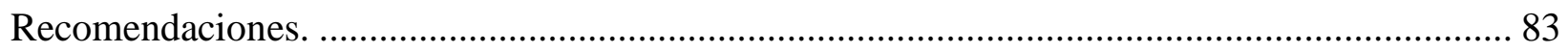

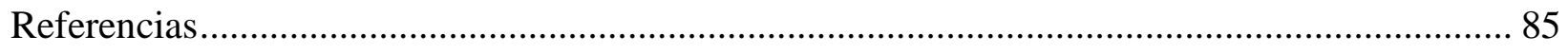

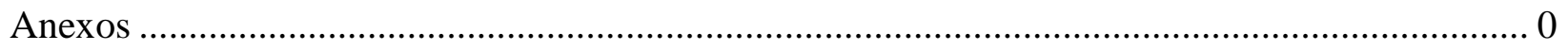


Cuestionario de Impacto de las campañas de telemercadeo en el sector bancario.

\section{Lista de Figuras.}

Grafica 1. Evolución de la suscripción a telefonía móvil en Colombia (1994 - 2T 2012)........ 30

Gráfica. 1.2 Índice de penetración de telefonía móvil en Colombia (1T 2010 - 2T 2012)...... 31

Gráfica. 2 Evolución trimestral de la suscripción a telefonía móvil en Colombia (1T 2010 - 2T

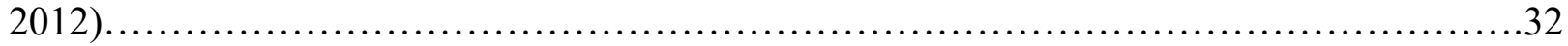

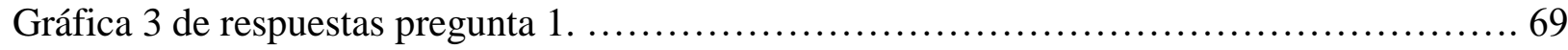

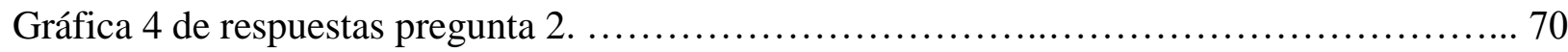

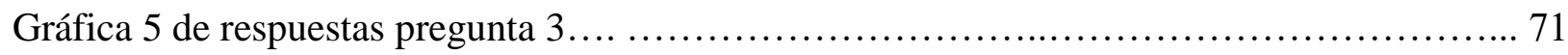

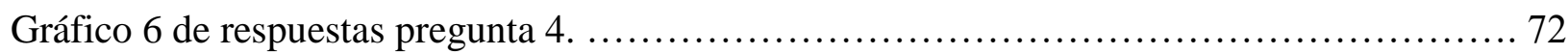

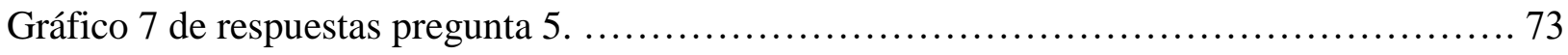

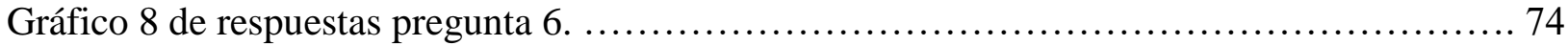

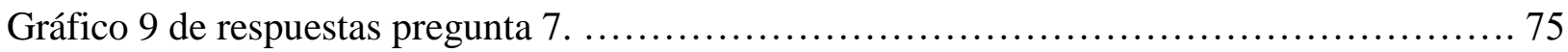

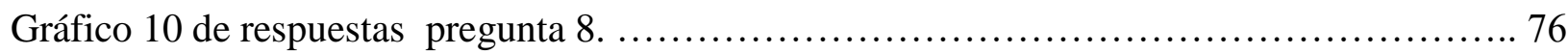

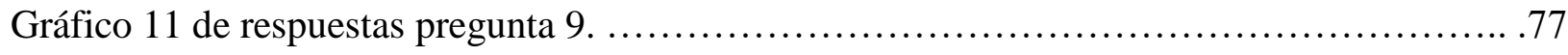

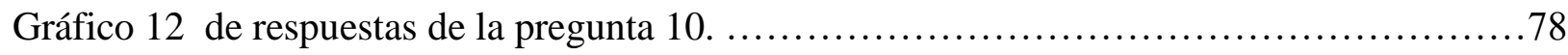

Tabla Número 1: Respuestas Expertos................................................... 70

Tabla Número 2: Respuestas Expertos................................................ 71

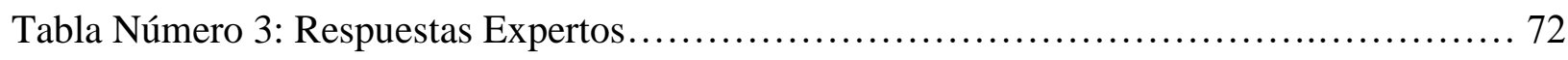

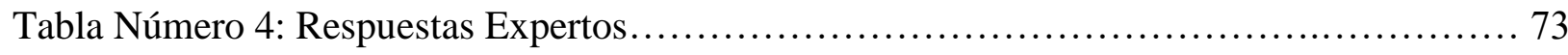

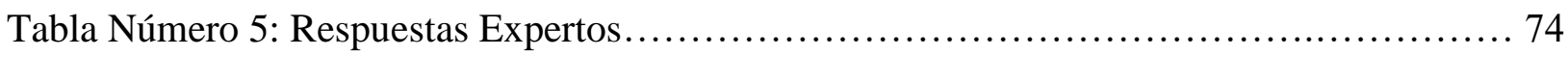

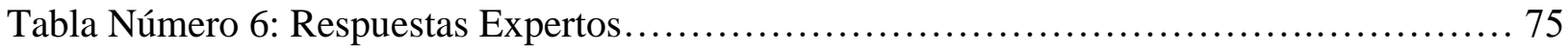

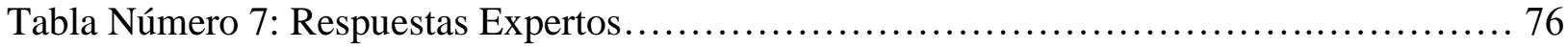

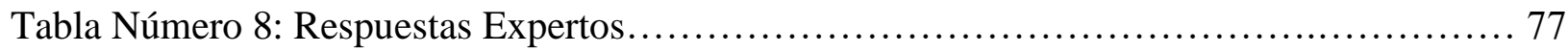

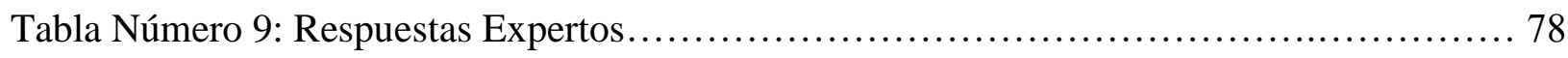

Figura 1 Principales acciones para llevar a cabo la investigación-acción....................... 64

Figura 2 Método en acción utilizando el Proceso cualitativo. .................................66 


\section{Introducción.}

Esta investigación consiste en diseñar y ejecutar un cuestionario soportado por un modelo cualitativo que busca evaluar la opinión de personas que estén involucradas con el telemercadeo, para así poder determinar y valorar los principales aspectos que nos permitan establecer el impacto de las campañas de telemercadeo de las entidades del sector bancario para la captación de nuevos clientes, teniendo en cuenta las herramientas de comunicación entre los bancos y las personas, determinando si estas se aprovechan y generan así un impacto en la organización.

Con base en el modelo, se busca identificar la dificultad que presenta en la actualidad el telemercadeo para cautivar a la población Colombiana, dado que se evidencia una baja recepción por parte de las personas.

Para la elaboración del cuestionario, se hará una recopilación de datos bibliográficos que detallen los aspectos importantes del telemercadeo, para así estructurar el cuestionario a una muestra específica, el cual es grupo de personas con conocimientos en el tema de investigación planteado.

Este estudio es de provecho para bancos, que están involucrados constantemente en la búsqueda de personas, que son consideradas prospectos, para que se conviertan en clientes de la organización, también para profesionales del sector bancario, quienes se encargan de analizar resultados y generar planes que sirvan para la captación de nuevos clientes, a su vez para investigadores y estudios de campañas en general, para investigaciones y estudios de la materia. 
Por tal motivo, se va a hacer un recuento histórico de lo que fue y es en la actualidad el telemercadeo, luego se va a contrastar las diversas definiciones del telemercadeo frente a varios autores, después se realizara una recopilación bibliográfica de las principales características que la componen, para finalmente elaborar y ejecutar el cuestionario que permita evaluar cuál es el impacto de las campañas de telemercadeo en la captación de nuevos clientes. 


\begin{abstract}
.
This research is capable of designing and executing a qualitative questionnaire that seeks to evaluate the opinion of the people involved in telemarketing, in order to determine and evaluate the principles that allow the impact of the telemarketing campaigns of the Banking sector to attract new clients, taking into account the communication tools between banks and individuals, determining if they are used and thus generate an impact on the organization.
\end{abstract}

Based on the model, it is sought to identify the difficulty currently presented by telemarketing to captivate the Colombian population, since there is evidence of a low reception by the people. For the elaboration of the questionnaire, a collection of bibliographic data has been established that details the important elements of the telemarketing, in order to structure the questionnaire to a sample that includes a group of people with knowledge in the subject of the raised investigation.

This study is useful for banks, which are constantly involved in finding people, who are considered prospects, to become the clients of the organization, also for professionals in the banking sector, who are responsible for analyzing results and generate Plans that serve to attract new clients, once for researchers and campaign studies in general, for research and studies of the subject.

For this reason, a historical account will be made of what telemarketing was today, then the various definitions of telemarketing will be contrasted with several authors, after a bibliographical compilation of the main characteristics that compose it, finally elaborate and execute the questionnaire that allows to evaluate the impact of the telemarketing campaigns in the recruitment of new clients. 


\section{CAPITULO I}

\section{Planteamiento del problema.}

El telemercadeo es el "uso innovador de equipos y sistemas de telecomunicaciones como parte de la categoría de ventas personales que es "dirigida al cliente", en especial para productos que se pueden comprar o adquirir sin necesidad de ser vistos" (Stanton, Etzel, \& Walker, 2007), y por ello las organizaciones, han hecho uso del telemercadeo, como "estrategia de divulgación para la venta de productos y servicios, por canales alternativos" (Prime Contact Center Solutions S.A., 2012), debido a las mejoras tecnológicas y a la demanda en el sector de la telefonía móvil, según la revista semana citando al MinTIC “en Colombia hay más celulares que personas, puesto que en el país el total de abonados a telefonía móvil fueron 53.583.664 para un número de habitantes que no superaba los 48 millones" (Semana, 2015) (MinTIC, 2014), lo que para las organizaciones es una ventaja porque les permite contactar con facilidad a las personas, además “construir y mantener una buena relación con las personas, dado que las organizaciones pueden conocer las necesidades de estos y asimismo informar sobre nuevos productos" (Telemarketing. La red como soporte de marketing y comunicación, 2007).

De acuerdo al DANE “en Colombia para el año 2015 había un aproximado de 48.312.962 habitantes y se encontró que el 95,6\% de los hogares al menos una persona poseía teléfono celular" (DANE, 2015), ante estas cifras, las organizaciones y su conexión con las personas podría considerarse más factible para la realización de una campaña de telemercadeo, a pesar de esto, la preocupación radica en conocer si ante las posibilidades existentes de contactar a una persona que puede ser considerada como prospecto, y posiblemente convertirse en cliente, si realmente las organizaciones están aprovechando tanto las herramientas de comunicación 
disponibles tanto aquellas que poseen como organización como aquellas a las cuales las personas tienen a su disposición, y que sirva de beneficio para las organizaciones en la captación de nuevos clientes. 


\section{Objetivos.}

\section{Objetivo general.}

Evaluar el impacto de las campañas de telemercadeo de ventas en la captación de nuevos clientes en entidades del sector bancario.

\section{Objetivo específico.}

- Identificar a través de una exploración bibliográfica los aspectos que deben considerarse para evaluar al impacto en torno a las campañas de telemercadeo en el sector bancario.

- $\quad$ Elaborar de un cuestionario en el que se identifiquen y se evalúen los principales aspectos que permitan establecer el impacto de las campañas de telemercadeo de las entidades del sector bancario para la captación de nuevos clientes.

- $\quad$ Evaluar los resultados obtenidos de la aplicación del cuestionario. 


\section{Justificación.}

La razón por la cual se ha afianzado por tantos años el telemercadeo en las organizaciones del sector bancario, es la capacidad de lograr una ventaja competitiva al momento de conseguir una venta o promoción de un producto o servicio de forma directa, no presencial y practica (Fundamentos de Marketing, 2007, pág. 459). Dentro de los beneficios del telemercadeo está la comunicación directa con las personas, y la facilidad de edificar el crecimiento de la empresa en términos de incrementos de los niveles de ventas y servicios ofrecidos por esta.

Es importante conocer el impacto de las campañas de telemercadeo, dado que brinda una percepción de la aplicabilidad de la herramienta en la actualidad, teniendo en cuenta las nuevas tendencias tecnológicas en cuento a la aplicación en la población, dado que representa una nueva barrera para las organizaciones, de confrontar las nuevas tendencias de los usuarios en cuanto al uso de las tecnologías fundamentadas en el uso del teléfono. 


\section{Hipótesis.}

Como se mencionó anteriormente, el amplio mercado de telecomunicaciones e interconectividad en Colombia (DANE, 2015) establece que "en Colombia hay más celulares que personas". Según el informe presentado por el Ministerio TIC, al finalizar el año 2015, en donde el total de abonados a la telefonía móvil fueron 53.583.664, mientras que el número de habitantes no supera los 48 millones." (TIC, 2014) (Semana, 2015), siendo este un espectro complejo, y en comparación con el poco mercado que logra abarcar de campañas de telemercadeo en el sector bancario (TIC, 2014) el cual tan solo se ejecutó un total 7.263.592 de llamadas telefónicas a Colombianos lo que representa alrededor de un $15 \%$ a nivel nacional, del las cuales tan solo un 5\% se logró una continuación de la llamada (Asociación Colombiana de Contact Centers y BPO, 2015), lo que pone en la mesa es el impacto de la misma y a su vez cuestiona que tan eficaz es sobre el total del mercado que puede llegar a explotar (Genesys, 2008), se evidencia entonces una dificultad en la captación de nuevos clientes, a su vez el tratar de consolidar gran mercado que puede llegar a ser en términos de comunicaciones.

En este orden de ideas viendo estas dificultades se plantean, se evidencia que las campañas de telemercadeo efectuadas por entidades del sector bancario no tienen el impacto deseado, es decir que no están logrando en su totalidad la captación de nuevos clientes y que a su vez adolecen de herramientas que propicien o faciliten una interacción fluida entre las empresas y las personas. 


\section{CAPITULO II}

\section{Revisión literaria.}

Para afrontar este trabajo, es necesario conocer cómo se conformó el telemercadeo desde sus inicios, por tal motivo se desarrollara todo un recorrido desde el ámbito global pasando por lo conceptual e ingresando a lo especifico en torno al telemercadeo, lo que permitirá acertar en la información recolectada y a su vez en la elaboración del instrumento que nos dará las bases necesarias para así conformarlo desde sus raíces y acertar con el comprender la importancia de medir el impacto del telemercadeo en las organizaciones del sector bancario.

A continuación se desplegará todo un recorrido histórico, teórico en torno a la conformación del telemercadeo, en el mundo hasta enfocarlo en Colombia, esto desplegará todo un estudio puntual del tamaño del mercado en torno al telemercadeo en Colombia que permitirá entender la dimensión de lo que se pretende evaluar en este estudio.

\section{Marco histórico.}

En 1876 el inventor Alexander Graham Bell es reconocido por patentar el primer medio de comunicación eficaz de larga distancia entre dos personas que se encuentren a gran distancia "el teléfono" se convierte en una eficiente herramienta de comunicación para todo tipo de persona, a este elemento de comunicación se le dan diversos usos en la vida cotidiana. Graham Bell a su vez crea su propia empresa y una fuerte comercialización telefónica por todo Estados Unidos creando las primeras centrales telefónicas y los primeros anuncios en las Páginas Amarillas (Groundwater, 2005), que le dan la posibilidad de que cada persona tenga en un gran libro los números de la personas a la cual desea contactarse de una forma más sencilla, lo único que debía hacer era buscar el número de contacto de esa persona. 
Aunque en Estados Unidos y en diversos países mientras se adaptó este medio de facilidad de comunicación, desde sus inicios fue poco recibido al existir las empresas operadoras de teléfono que se encargaban de entablar la comunicación (Pereira, 2005).

"Por más de 50 años, las operadoras telefónicas eran encargadas de que hacer todas las conexiones entre las personas a las cuales deseaban comunicarse. Estas operadoras que en su mayoría eran mujeres se les entrenaban adecuadamente para poder comunicarse entre el que llamaba y el que deseaba recibir la llamada con el fin de facilitar la comunicación. Por otro lado, a las operadoras se le daba una capacitación básica para en caso de que fuese necesario, pudieran ofrecer o vender por medio del teléfono las extensiones y equipos telefónicos que ellos mismos operaban” (Pereira, 2005, pág. 23).

De esta forma y por mucho tiempo fue evolucionando la comunicación y la interconectividad telefónica en diversas partes no solo de Estados Unidos, sino también en el resto del mundo, de manera tal que fueron adaptando el teléfono en cada una de sus locaciones y a cada una de sus necesidades.

Fue así como para el año 1881, año en el que era completamente desconocido el término de telemercadeo, el pastelero Berlinés "Kranler" comenzó a ofrecer por primera vez sus bocadillos por medio telefónico, esta estrategia le fue tan eficaz que en poco tiempo logro multiplicar sus ventas, creando su propia fábrica de bocadillos (Thirion, 2010). Pero para aquel entonces el término se estaba hasta ahora acuñando y no se tenía una plena certeza de cómo era que este operaba directamente en sus diversas maneras en términos de telemercadeo.

Fue entonces que en el año 1889 la empresa Bell Telephone, paso a trasformare como la empresa AT\&T, pionera en el uso del teléfono en el mercadeo. Puesto que estos fueron los 
primeros en crear un Centro de Telemercadeo ubicado en la ciudad de Kansas, EEUU, que tenía como objeto el desarrollo de técnicas para cubrir sus propias necesidades internas, así como para enseñar a sus clientes a usar eficazmente el telemercadeo para que ellos supieran ofrecer sus productos o servicios a otras personas (Pereira, 2005). Lo que en parte funciono para algunos fue una completa pérdida de tiempo para otros, pues esta aun no era una técnica $100 \%$ viable.

\section{La primera campaña de telemercadeo.}

Para el año 1962, en el gran auge automovilístico que vivía la compañía Ford, se dieron a la tarea de fortalecer sus ventas, por tal motivo le delegaron la gran responsabilidad a la compañía "Lee Iacocca" empresa de publicidad y mercadeo que por primera se encargaría de realizar una campaña de "mercadeo telefónico", que estaba proyectada para contactar aproximadamente a 20 mil personas, con el objetivo de concertar un mínimo de 2 entrevistas diarias para cada uno de sus 23 mil vendedores de autos, como resultado obtuvieron un gran volumen de ventas, siendo la campaña de telemercadeo todo un éxito (Thirion, 2010).

Entre 1968 y 1969, se establece el sistema de venta por teléfono en Panamá, Ecuador, Jamaica, Costa Rica, entre otros países latino americanos, que pretendían ofrecer inicialmente publicidad por medio de las "Páginas Amarillas", que eran Guías Telefónicas, para ITDS, (International Telephone Directory Service), que producía los directorios telefónicos oficiales de todos esos países y que permitía conectar a los compradores con los vendedores (Pereira, 2005).

Para 1984 en el Boom del Telemarketing la "Direct Marketing Association" daba a conocer que existía en los EE.UU. unos 30,000 centros telefónicos internos de empresas que ofrecían sus productos y servicios. Se estimaba que en 1995 más de 750,000 personas en los Estados Unidos se estaban dedicando al Telemarketing (Pereira, 2005). 
En los últimos años, se ha formalizado una incipiente demanda por parte de las empresas de todo el mundo, dado que las empresas se ven inquietas por la forma dar a conocer sus productos y ofrecer sus servicios, tanto así de qué forma paralela se han desarrollado abruptamente las empresas especializadas llamadas Call y Contact Center para atender estas prontitudes en específico.

Para comprender la magnitud de este mercado cabe destacar que en la actualidad "para el 2006 ya había pasado los 967,7 millones de euros, en ventas por medios telefónicos en el mundo" (Villa, 2007), es decir, el telemercadeo tomo gran importancia y debido a ello tuvo que evolucionar, para acoplarse tanto a las nuevas tendencias, a nuevas tecnologías como al aumento de la demanda por el incremento constante de la población, que involucra a su vez buscar estrategias para la captación de más clientes.

\section{Marco conceptual.}

Para comprender cómo se lleva a cabo la aplicación de una campaña de telemercadeo en el sector bancario, se expondrán algunas definiciones que darán mayor información de cómo se conforman.

\section{Diversos significados de las campañas de telemercadeo.}

Los significados que se muestran a continuación fueron tomados de Prime Contact Center Solutions, empresa Colombiana especializada en campañas de Call y Contact Center que divulga un glosario pertinente para el estudio, con lo cual se pretende contrastar los diferentes significados de Telemercadeo provenientes de diversos autores. El significado que le da esta empresa al término de telemercadeo es: 
- “Telemarketing: Estrategias de divulgación y venta de productos y servicios, por canales alternativos (diferentes a contacto presencial). Puede ser activo o receptivo." (Prime Contact Center Solutions S.A., 2012).

Al investigar a profundidad como es que se concibe el término de telemercadeo según reconocidos autores que han utilizado el telemercadeo dentro de sus diversos estudios y libros encontramos que;

En primer lugar el Telemercadeo es el "uso innovador de equipos y sistemas de telecomunicaciones como parte de la categoría de ventas personales que esta "dirigida al cliente”, según (Stanton, Etzel , \& Walker, 2007), al profundizar en el significado, rescatándolo de un contexto organizacional, ellos definen que el telemercadeo es también “Llamado en ocasiones ventas telefónicas, (...) que se refieren a que un vendedor inicia el contacto con un comprador potencial y cierra una venta por un medio telefónico" (Fundamentos de Marketing, 2007, pág. 459).

En ese sentido se percibe que el telemercadeo es modelo de ventas, en el cual la empresa busca conquistar al cliente por medio telefónico.

\section{Enfoque principal de las campañas de telemercadeo.}

Al comprender que es el telemercadeo, se puntualiza que este va dirigido a todo aquel "comprador potencial o real de productos o servicios" (A.M.A, American Marketing Association, 2017). El cliente, es quien le da vida a las campañas de telemercadeo, sin él no se obtendrían las ventas que requieren las organizaciones para generar utilidades. Así mismo, se vislumbra que las organizaciones por medio de las campañas de telemercadeo ofrecen a sus 
clientes productos y servicios, que atienden las necesidades de los mismos, con el objeto de comprender esto mejor, a continuación hay una breve explicación de la Asociación Americana de Marketing la cual menciona que un producto es;

Un conjunto de atributos (características, funciones, beneficios y usos) capaces de intercambiar o usar; Generalmente una mezcla de formas tangibles e intangibles. Así, un producto puede ser una idea, una entidad física (un bien) o un servicio, o cualquier combinación de los tres. Existe el propósito de intercambio en la satisfacción de los objetivos individuales y organizacionales (A.M.A, 2017, pág. 16).

Por otro lado la (Asociacion Americana de Marketing ) explica que el servicio, visto desde 2 perspectivas;

1. "Los productos, como un préstamo bancario o de seguridad en el hogar, que son intangibles o al menos sustancialmente. Si son totalmente intangibles, se intercambian directamente de un productor a otro, no pueden ser transportados o almacenados, y no son perecederos. Los productos de servicio son a menudo difíciles de identificar, porque entran en existencia al mismo tiempo que se compran y consumen. Comprenden elementos intangibles que son inseparables; Por lo general implican la participación del cliente de alguna manera importante; No pueden ser vendidos en el sentido de transferencia de propiedad; Y no tienen título. Hoy en día, sin embargo, la mayoría de los productos son en parte tangibles y en parte intangibles, y la forma dominante se utiliza para clasificarlos como bienes o servicios (todos son productos). Estas formas híbridas comunes, cualesquiera que sean llamadas, pueden o no tener los 
atributos que se dan sólo para servicios totalmente intangibles” (A.M.A, 2017, pág. 19).

2. "Servicios, como término, también se utiliza para describir las actividades realizadas por los vendedores y otros que acompañan a la venta de un producto y ayudar en su intercambio o su utilización (por ejemplo, accesorios de calzado, financiación si se realizan durante la venta, se consideran partes intangibles del producto" (A.M.A, 2017, pág. 19).

De tal modo que es relevante observar que en todas las organizaciones en especial las del sector bancario, pueden flexibilizar su modelo de negocio para así poder ofrecer a sus clientes productos y servicios que se adapten a las necesidades de los mismos. Como lo evidenciamos en el sector bancario estos pueden llegar a ofrecer productos como lo son tarjetas de crédito, seguros de todo tipo, afiliaciones, entre otros que se traducen en la prestación de un servicio o la compra de un producto tangible o intangible.

Ahora bien, es conveniente precisar que el Contact Center es "el punto de contacto entre el cliente y la empresa, (...) la cual a través de medios de comunicación como lo son, la vía telefónica, el correo electrónico, el chat y la comunicación multimedia por Internet. (Morris, Ancajima, Galindo, Guido, \& Mejía, 2009). En este sentido, es entendible que el Contact Center sea el encargado de realizar las campañas de telemercadeo, por el mismo sentido de que estos cuentan con los conocimientos y los recursos necesarios para poder llevar procesos de comunicación telefónica con los clientes.

Según se ha descrito observamos que las campañas de telemercadeo se desarrollan en los Contact Center y van dirigidos a clientes potenciales, con el fin de ofrecerles productos y 
servicios por medios telefónicos. Si bien, se presentan grandes oportunidades de mercado por la accesibilidad de comunicación con los clientes.

De esta forma entendemos que para las organizaciones les es necesario que haya algún tipo de acercamiento u ofrecimiento de los productos y servicios que elaboran, como es el caso del sector bancario, que justamente ha sido uno de los mayores involucrados en términos de telemercadeo, al ver que este modelo de ventas se ajusta plenamente con los productos y servicios financieros que estos ofrecen, a la vez dando cuenta de que para brindarles a estos no hay necesidad de que el cliente tenga que acarrear mayores complicaciones para obtenerlo. Por el contrario, se facilitan múltiples procesos y facilitan la interacción con las empresas, reduciéndoles los esfuerzos de la misma manera.

\section{Instituciones financieras, comprendidas en sector bancario bajo un modelo de} telemercadeo.

Es pertinente entender con antelación que el sector bancario es "el conjunto de instituciones (previamente autorizadas por el Estado), que se encargan de captar, administrar e invertir el dinero tanto de personas naturales como de personas jurídicas (nacionales o extranjeras)" (Prieto, 2008). Si bien es cierto que las personas naturales y jurídicas demandan productos financieros, es apropiado señalar que estos pueden ampliarse dentro de un gran portafolio de opciones, ilustramos algunos de estos como lo son "las tarjetas de crédito, las suscripciones a revistas y las afiliaciones a clubes deportivos." entre otros... (McCarthy \& O’Donnell, 2002). 


\section{Definiciones comunes de las Campañas de Telemercadeo.}

Si bien se mencionó inicialmente que;

El Telemercadeo "Es el uso innovador de equipos y sistemas de telecomunicaciones como parte de la categoría de ventas personales que esta "dirigida al cliente"” según (Stanton, Etzel , \& Walker, 2007), al profundizar en el significado rescatándolo de un contexto organizacional, ellos definen que el telemercadeo es también "Llamado en ocasiones ventas telefónicas, (...) que se refieren a que un vendedor inicia el contacto con un comprador potencial y cierra una venta por un medio telefónico" (Stanton, Etzel , \& Walker, 2007). Se observa que desprenden dos definiciones;

La primera es como lo mencionamos anteriormente "El uso innovador de equipos y sistemas de telecomunicaciones", (Stanton, Etzel , \& Walker, 2007) de primera mano el telemercadeo expresa directamente que este no es únicamente el uso exclusivo del teléfono, por lo contrario es un significado que se adapta a las nuevas demandas de los consumidores de estar intercomunicados por diferentes medios de comunicación como lo son el Chat, los mensajes de texto, Teléfono celular y finalmente encontramos el más antiguo de todos el teléfono fijo, estos medios de comunicación permiten que el telemercadeo se establezca en un parámetro de forma directa e indirecta con el cliente (Fundamentos de Marketing, 2007).

El segundo significado, según (Diccionario de Enciclopédico Océano, 1997) se pasa a la importancia del uso del teléfono para poder promover una venta con el cliente que viene a ser un proceso complementario a lo que hace la fuerza de ventas, lo que incentiva a que se complementen sus actividades; por lo contrario lo que se busca es adaptar y flexibilizar a las necesidades del cliente, como una forma de diversificar los medios de hacer llegar los productos 
o los servicios a los clientes, adicionalmente establecer una campaña de telemercadeo ahorra el tiempo de desplazamiento de un cliente para poder adquirirlo y los costos se trasladarían según la industria (Fundamentos de Marketing, 2007).

\section{Glosario de términos utilizados en campañas de telemercadeo.}

A continuación se darán a conocer diversos significados que son oportunos conocer con anterioridad para así poder entrar a estructurar el estudio del impacto de las campañas de telemercadeo en el sector Bancario, la terminología que en su mayoría es utilizada dentro de las empresa tele operadoras.

- Benchmarking: Método de comparación de una empresa con sus similares, en métricas definidas.

- Call Center: Procesamiento integrado de altos volúmenes de llamadas, como resultado del ejercicio del negocio.

- Contact Center: Central de contacto multi - canal: voz (red telefónica convencional, ip, celular), fax, email, chat, web).

- Campañas Inbound o Receptivas: Proyecto dedicado a la atención de contactos realizados por el cliente/usuario. Frecuentemente utilizadas como soporte de pautas publicitarias masivas o de mercadeo directo.

- Campañas outbound o activas: proyecto para la realización de contactos a clientes y/o usuarios.

- CRM (Customer Relationship Management): Filosofía de visión global del cliente, a través de la integración de toda la información existente en la organización. Requiere de herramientas de soporte para registro, control y seguimiento de las interacciones. Busca personalizar la relación para rentabilizar al cliente. 
- Outsourcing ("tercerización”): Contratación de recursos externos para la ejecución de operaciones, procesos y/o tareas.

- Reportes Históricos: Reportes que monitorean el desempeño de los agentes y del call center durante un período de tiempo

- Inbound: Volumen de contactos que ingresan al sistema

- Outbound: Contactos realizados por el sistema

- Focus Group: Técnica de investigación de mercados. Selección de un grupo de clientes según un conjunto de criterios definidos. Investiga sobre productos, hábitos y comportamientos, en forma subjetiva, dentro de una sesión de conversación dirigida. (dinámica de grupo).

(Prime Contact Center Solutions S.A., 2012)

La terminología citada es utilizada contantemente en la ejecución de campañas de telemercadeo, la cual se hace necesaria el momento de referirse a ciertos elementos o componentes que son característicos dentro de las campañas, por lo cual es de importancia conocerlas y utilizarlas adecuadamente para este tipo de estudios investigativos, de esta forma se podrá analizar a profundidad los principales componentes que son usualmente utilizados para la conformación de las campañas de telemercadeo.

\section{Marco teórico.}

Investigar los diversos estudios que se han formulado alrededor de las campañas de telemercadeo, nos permitirá destacar de los principales elementos y características que las conforman, de manera tal que nos topemos en los diversos factores que determinan si se puede 
llegar a encontrar relación del impacto de las campañas de telemercadeo en las organizaciones del sector bancario, al igual ver que tanto mercado es el que este abarca en razón del amplio mercado de telecomunicaciones que hay en Colombia.

\section{Evolución de las campañas de telemercadeo en Colombia.}

Para comprender como se elaboran y se ejecutan las campañas de telemercadeo en el sector bancario colombiano, es importante revisar los estudios que se han hecho con anterioridad y examinar cómo se han formulado estas. De modo tal que en Colombia concuerda con la idea de que en el "sector bancario ha habido un incremento considerable de las campañas de telemercadeo" ( Corporación Financiera Internacional , 2009),

Por otro lado, un estudio realizado por la empresas empresa Génesys, que es uno de los principales proveedores de plataformas de desarrollo que facilitan la ejecución campañas de telemercadeo alrededor del mundo, habla en uno de sus estudios que para Colombia ha pasado a ser uno de los mayores proveedores de la plataforma ofreciendo sus productos de Contact Center a grandes empresas, se destaca que para el año 2000 tenían un consolidado de 22 empresas tele operadoras en Colombia, y para el año 2008 alcanzaron alrededor de los 57 empresas que ejecutan servicios telefónicos ya sea por tercerización o directamente (Genesys, 2008, pág. 6).

\section{El telemercadeo empleado desde diversas herramientas de comunicación.}

Un estudio de la Universidad Javeriana muestra cómo se han presentado innovadoras maneras que subyacen del telemercadeo, como nuevas formas de ofrecer productos y servicios, como lo son "mensajes de texto, video llamadas, mensajes de voz entre otros" (Javeriana, 2008), que han sido relacionados en la conformación de las campañas de telemercadeo y que a su vez 
han resultado exitosos en la implementación de estas nuevas estrategias en las campañas de telemercadeo.

\section{Uso de las campañas de telemercadeo en el sector bancario}

Las campañas telemercadeo se han aplicado en numerosos sectores empresariales, uno de los más destacados es el sector bancario, que evidentemente se ha venido desarrollando en gran medida por la facilidad de dar a conocer los nuevos productos financieros por su facilidad intangible de crearlos o cargarlos sin necesidad de mayores traslados, lo que se observa en un estudio realizado en Colombia, reflejó que para el año 2015 se alcanzaron sumar alrededor de 2 billones de pesos en ventas por medios telefónicos en el sector bancario, y que aproximadamente el 77,4\% de los colombianos tienen algún producto financiero, ya sea ofrecido por medio de una campaña de telemercadeo o por medio de oficina (Banc.Oportunidades, 2015).

\section{Nuevas tecnologías mayores facilidades.}

Precisamente una investigación de la (Javeriana) afirma que "en Colombia se ha tenido una gran acogida por la venta telefónica, lo que indica que cada vez más las ventas presenciales tienden a desaparecer." (pág. 52). En este orden de ideas, con la llegada de las nuevas tecnologías y con la apertura de nuevos medios de comunicación, crearon la posibilidad de que las empresas estuviesen mucho más cerca de sus clientes utilizando en especial los "medios electrónicos". Un claro ejemplo es el uso del celular, que se ha convertido en una herramienta de usó personal y diario, que a su vez a que ha resultado como "un método extendido y eficiente para establecer contacto con prospectos y concretar ventas" (U.Autónoma, 2013). En efecto se facilita la comunicación al tener una comunicación directa con el cliente. 


\section{Crecimiento del mercado de las telecomunicaciones en Colombia}

\section{Uso de telefonía móvil en Colombia.}

Algo sorprendente que ha venido creciendo abruptamente en Colombia es el uso de medios de telecomunicación en la población Colombiana, algo que es muy diciente al tratar de comprender lo extenso que llega a ser el mercado en el momento de ofrecer un producto o servicio por medio de una campaña de telemercadeo, teniendo en cuenta el crecimiento en torno al uso de las TIC, que son la principal fuente de conexión entre las empresas que ofertan productos financieros o de otra índole y los receptores que son los posibles clientes que se podrían llegar a crear por medio de una simple llamada.

“En Colombia hay más celulares que personas”. Según el informe presentado por el MinTIC, al finalizar el año 2014, el total de abonados a la telefonía móvil fueron 53.583.664, mientras que el número de habitantes no supera los 48 millones.” (TIC, 2014) (Semana, 2015).

Lo que al igual se refleja según un estudio de la Superintendencia de Industria y Comercio de Colombia que muestra la evolución del número de suscriptores a teléfonos móviles en Colombia, lo que se muestra que hasta el año 2012 venia una incipiente demanda de teléfonos móviles que a su vez son importados en masa desde otros países en especial la China (Sánchez, Lis, \& Herrera, 2012). 


\section{Grafica 1. Evolución de la suscripción a telefonía móvil en Colombia (1994 - 2T 2012)}

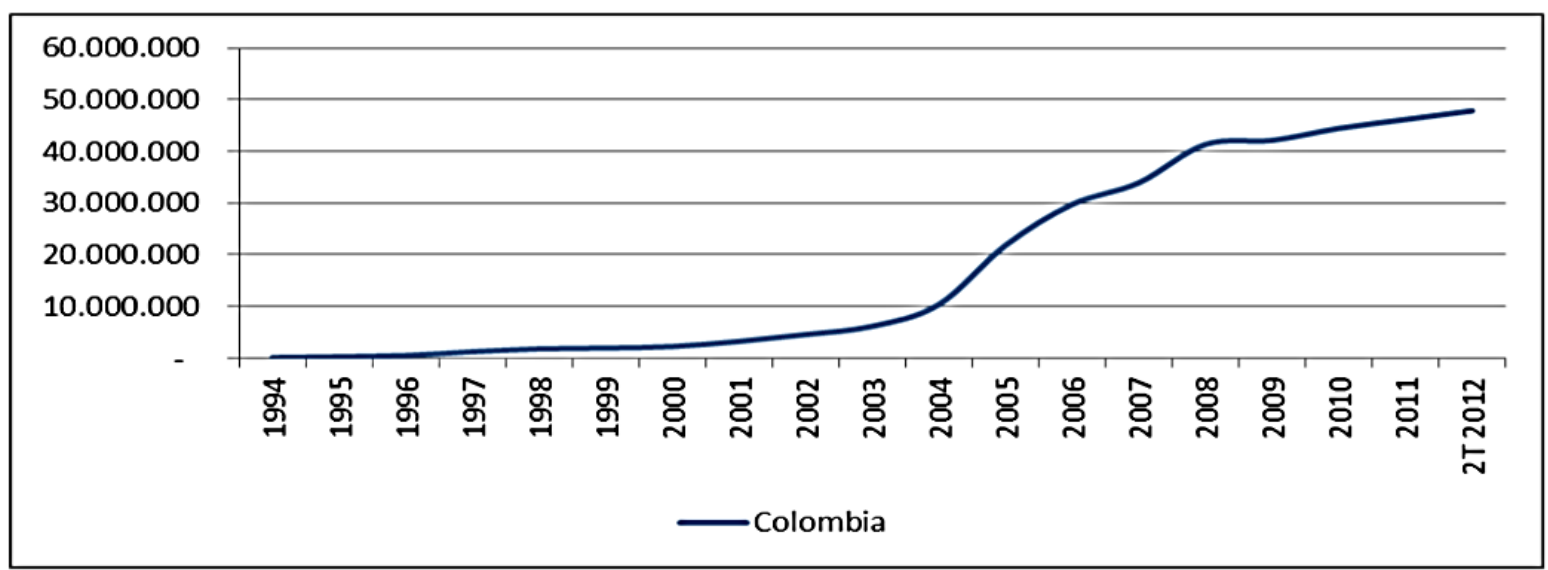

Fuente: GEE- SIC a partir de cifras del Banco Mundial y del Ministerio TIC

"En cuanto a telefonía celular, Colombia ha registrado una dinámica de penetración muy alta. Según datos del Banco Mundial, los abonados a telefonía celular en 1994 eran 86.805; en 2000 ascendían a 2.256.801; en 2011 habían alcanzado 46.200.421 y de acuerdo con las cifras del Ministerio TIC, al segundo trimestre de 2012, las líneas suscriptas eran 47.885.376. En la Gráfica superior se aprecia esta evolución. El número de líneas es 532 veces superior a las vigentes en 1994" (Sánchez, Lis, \& Herrera, 2012, pág. 38).

El aumento desproporcionado de la penetración de teléfonos celulares en Colombia ha permitido el acceso a nuevos segmentos de clientes en las campañas de telemercadeo, lo que se mostrara a continuación, no solo refleja el obstáculo de poder entablar una comunicación con los clientes, sino que a su vez muestra la necesidad de optimizar los procesos, mejorar el alcance y segmentar adecuadamente a los clientes para efectivamente dar una comunicación certera telefónicamente (Rafael Muñiz, 2005). 
Gráfica. 1.2 Índice de penetración de telefonía móvil en Colombia (1T 2010 - 2T 2012)

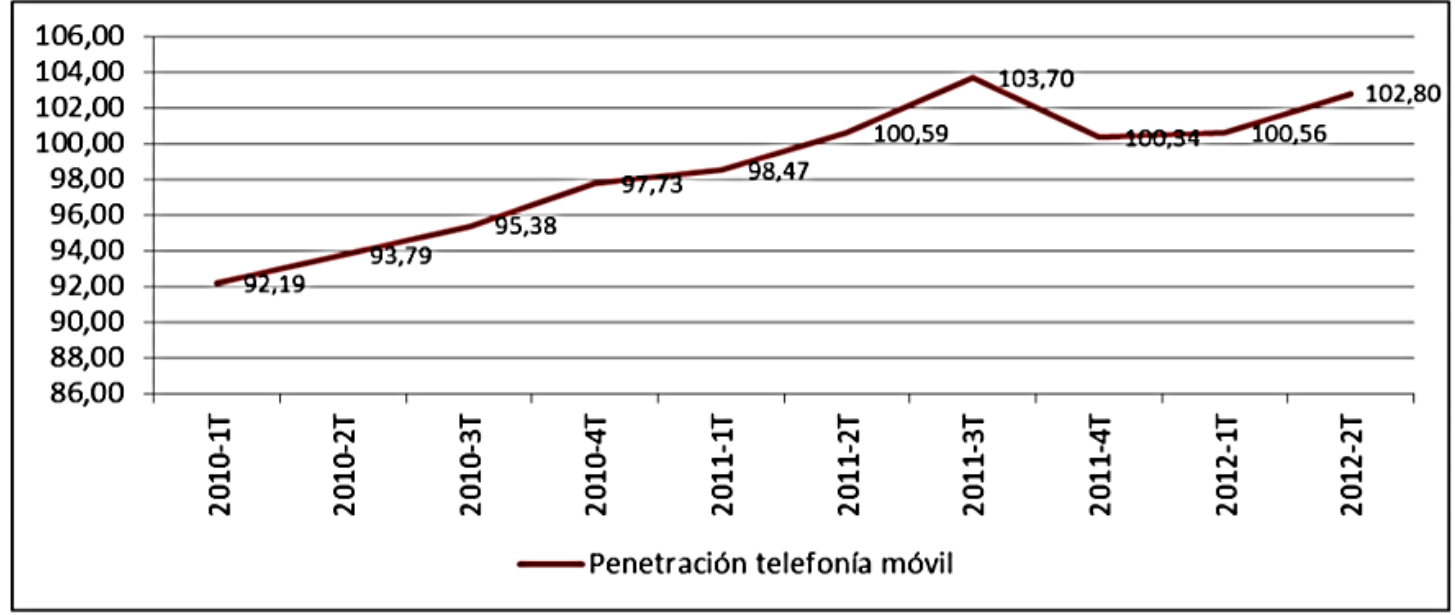

Fuente: GEE- SIC a partir de cifras del Ministerio TIC.

De acuerdo con los planteamientos anteriores, se deduce que hay que determinar en Colombia como ha ido creciendo en términos de TIC (Tecnologías de la información y de la comunicación), el uso de nuevas tecnologías, que han permitido saber el margen de mercado a la cual se puede apuntar una campaña de telemercadeo.

\section{Gráfica. 2 Evolución trimestral de la suscripción a telefonía móvil en Colombia (1T}

2010 - 2T 2012)

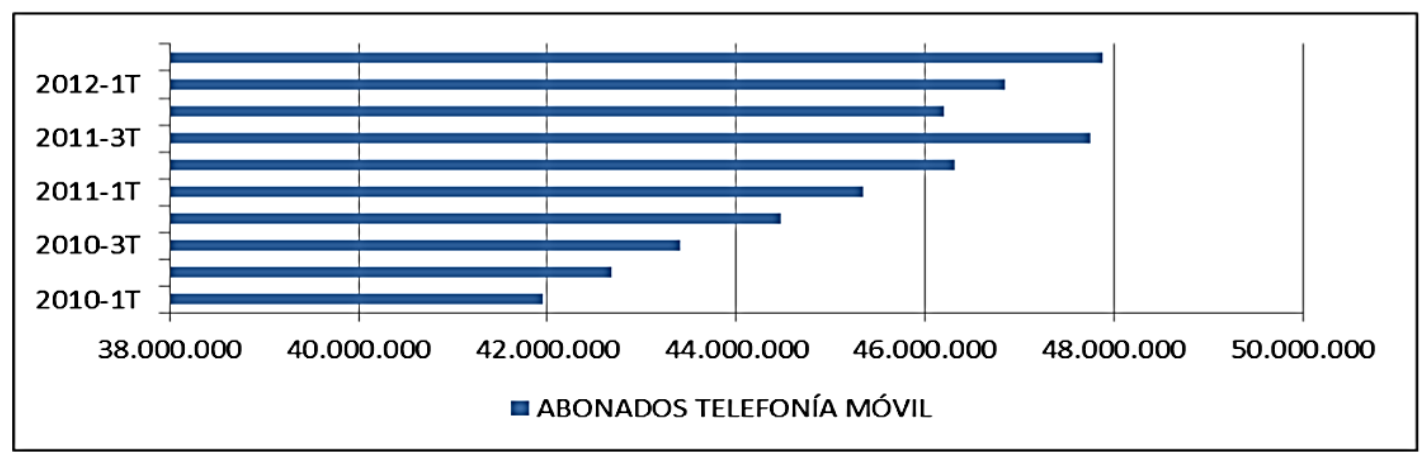

Fuente: GEE- SIC a partir de cifras del Ministerio TIC. 
La magnitud del uso de telefonía móvil se ha disparado desde al año 2010, comparándolo con el año 2012, puesto que según cifras se observaba que este número igualaba casi el número de habitantes en la región. Lo refleja puntualmente el Departamento Administrativo Nacional de Estadística que menciona que "en Colombia para el año 2015 había un aproximado de 48.312.962 habitantes y se encontró que el 95,6\% de los hogares al menos una persona poseía teléfono celular" (DANE, 2015). Esto no solo ejemplifica la magnitud que puede llegar a tener una campaña de telemercadeo, sino que a su vez da a conocer la complejidad de analizar la información que se recoge y optimizarla para efectuar resultados positivos. Cabe agregar que para el año 2002 se midió el "Volumen anual total del telemercadeo en el sector detallista alrededor del mundo y se encontró con una cifra de 275.000 millones de dólares" (McCarthy \& O’Donnell, pág. 26). Lo que resulta sorprendente, puesto que el crecimiento ha sido exponencial desde entonces; en gran medida por el auge tecnológico que ha facilitado la interconectividad a nivel mundial.

\section{Impacto de las campañas de Tele mercadeo en la sociedad.}

Para las empresas, una de las principales preocupaciones es lograr cautivar a sus clientes con el objetivo de que logren aumentar sus ventas, ahora bien, para que se lleven a cabo es pertinente que las campañas de telemercadeo no se reduzcan a operar un proceso de comunicación con el cliente y nada más, por el contrario, este proceso debe trascender por medio de una simple llamada, con el fin de que se logre realmente conquistar al cliente, y comience a formar parte de la empresa y así mismo comience consumir un producto o servicio (TIC, 2014).

Representa entonces, que hay que comprender a profundidad ¿qué es lo que realmente demandan los consumidores modernos?, lo que da a reflexionar el programador de Neuro 
Marketing Jürgen Klaric en su libro "Estamos ciegos", menciona la poca asertividad de las campañas de mercadeo en la actualidad, señalando de que no se logra el objeto propuesto por el simple motivo de que no se conoce que es lo que realmente demandan los nuevos consumidores, él en sus años de experiencia "no está de acuerdo con la manera como se investiga y se hace marketing en nuestra era", (pág. 12) de manera tal de que no concibe la forma en la que se analiza al cliente para tratar de entender cuáles son las verdaderas necesidades que este demanda, las campañas de mercadeo en especial las campañas de telemercadeo, se enfrascan en un mar de productos que no direccionan realmente las necesidades de los clientes. De tal modo que simplemente se pierde el tiempo ejecutándolas (Klaric, 2012).

\section{Marco referencial.}

El telemercadeo ha tenido múltiples trasformaciones en el trascurso del tiempo, aunque en esencia esta siga siendo la misma, sus principales características siguen reestructurándose y moldeándose a las prontitudes del entorno globalizado, es evidente que en forma genérica siempre habrá espacio para características que se cumplen en casi todos los casos en torno a las campañas de telemercadeo y sus principales elementos, pero lo que vale la pena rescatar es como estas se han destacado dentro de las organizaciones ya que han resultado bastante útiles para poder usarlas en diversos escenarios.

Es por ello que a continuación se darán a conocer diversas características que ejemplifiquen cómo es que en la actualidad se conforman las campañas de telemercadeo, respecto a cada uno de los elementos que se muestran a continuación hace parte de una amplia gama que permite comprender como estas se elaboran y se ejecutan, esto no solo permite confrontar cada uno de los principales elementos que hay dentro de las campañas de 
telemercadeo, sino que a su vez permitirá evaluar que tan eficientes están siendo estos procesos que serán puestos en mención dentro del instrumento, pues este será el que determine que tan pertinentes y adecuados son cada uno de estos elementos y si también estos se están llevando a cabo de forma apropiada.

\section{Importancia del Telemercadeo.}

El telemercadeo es una herramienta eficaz que le permite a las empresas entablar una comunicación directa con los clientes, reducir costos, y mejorar el desempeño de ventas de la empresa que pueden ser un obstáculo en otros tipos de campañas. El telemercadeo parte de consolidar una fuerte y frecuente comunicación con los clientes y a su vez formar nuevos prospectos y futuros clientes, edifica el crecimiento de la empresa, y permitirá a su vez conocer de cerca las necesidades que se generan en el transcurso del tiempo (Kazañetz, 2004).

El establecer un modelo de telemercadeo en una empresa obliga a generar una estrategia prominente que organice y visualice la empresa, una planificación constante le permitirá confrontar las nuevas necesidades que se afrontan al tener contacto directo con los clientes, viendo de cerca las prontitudes y adiciones que se van demandando (Rafael Muñiz, 2005).

\section{Usos del telemercadeo}

El telemercadeo sirve como una herramienta que permite establecer un contacto directo con actuales y la creación de posibles clientes, que trae consigo una variedad de funciones que sirve a las organizaciones para el desarrollo empresarial. Según (Vaca Zambrano \& Corella Parra) el telemercadeo tiene un variado rango de funciones que se muestras a continuación: 


\section{"Prospecto de clientes:}

Evaluar de manera anticipada al sujeto y conocer sus deseos, se debe determinar qué características se buscan en el futuro cliente, para saber si se encuentra o no dentro del mercado objetivo del producto o servicio que se ofrece.

\section{Generación de citas:}

Ahorrar tiempo y recursos monetarios en traslados y salas de espera para llegar a un acuerdo, ya que al concretar sus visitas de manera más efectiva y así optimizar su tiempo.

\section{Penetración en mercados:}

Sondear a nivel nacional o regional sin moverse de la oficina, de esta manera se puede conocer y medir el nivel de satisfacción de cada una de los clientes de una empresa.

\section{Dar servicios a cuentas:}

Conocer las opiniones y el estado de los clientes, mediante gestión de telemercadeo se puede hacer un seguimiento más minucioso, y poder medir el nivel de satisfacción de cada uno de los clientes de la empresa.

\section{Comercialización de bienes y servicios:}

Venta directa, se puede ofrecer productos y servicios, a un segmento de mercado determinado, sin que este salga de su casa u oficina. 


\section{Promoción y confirmación de eventos:}

Difusión inicial y seguimiento operativo, pudiendo medir la aceptación lograda dentro del mercado objetivo que se ha planteado.

\section{Llenado de cuestionarios:}

Este método es muy utilizado para realizar investigación de exploración, descripción y actualización de bases de datos anteriores.

\section{Toma de pedidos, opiniones, sugerencias y quejas:}

Permiten reforzar la operación de ventas, y como un medio interactivo de servicio al cliente.

\section{Dar seguimiento a ventas y transacciones:}

Brindar un servicio de post - venta a cada uno de los clientes.

\section{Investigación de mercados:}

Es utilizado como auxiliar en la recolección de datos o actualización de investigaciones anteriores, con información de los clientes".

(Vaca Zambrano \& Corella Parra, 2008, pág. 92)

\section{Ventajas y desventajas del telemercadeo.}

Dentro de los elementos relevantes cabe destacar que en comparación a otro tipo de campañas publicitarias y promocionales, las campañas de telemercadeo presentan una serie de 
ventajas y desventajas cuando estas se llevan a las organizaciones y se emiten hacia un público objetivo algunas de estas ventajas y desventajas se muestran a continuación:

\section{Ventajas.}

Las principales ventajas que da a conocer el autor José Manuel Sánchez Alvares, en su escrito sobre el Telemercadeo, habla de las principales causales de uso y motivos por los cuales es ventajoso utilizar las campañas de telemercadeo, cabe agregar de que este tipo de campañas se ajustan principalmente a cierto tipo de prototipos de sectores y empresas que cumplen con ciertas condiciones que se ajustan con las prontitudes que afronta el mercado (Álvarez Sánchez, 2007).

\section{Retroalimentación:}

En primer lugar, al ser el teléfono un medio específico respecto a una persona, permite evaluar al instante los aspectos más importantes de los programas de marketing directo. Además, el telemercadeo de entrada sirve como instrumento de apoyo a los programas de marketing que utilizan otros medios. El mayor uso del telemercadeo está en facilitar la respuesta de otros medios de marketing directo (correo, prensa y televisión).

\section{Flexibilidad:}

También la utilización del teléfono permite realizar modificaciones del programa sobre la marcha. Junto con la implementación de éste se puede ir probando y modificando los principales aspectos del mensaje y de la oferta. 


\section{Creación y mantención de actitud favorable entre ventas:}

Por medio del teléfono se puede construir y mantener una buena relación con los clientes. La empresa puede preocuparse de las necesidades de sus clientes y de la satisfacción que han logrado con los productos comprados a ella. Igualmente, puede informar a sus clientes del lanzamiento de nuevos productos.

\section{Aumento en el nivel de servicio.}

El teléfono provee un medio muy adecuado para servir al cliente. Este medio se puede utilizar para verificar los pedidos de los consumidores, para resolver las quejas y proveer una vía de comunicación expedita de la persona con la empresa. Procter \& Gamble implementó un sistema de servicio al cliente que redujo los reclamos en forma considerable y además le permite obtener información acerca de cómo mejorar sus productos y eliminar los defectos que ellos tienen.

\section{Alta productividad.}

El número de llamadas que se pueden realizar en un determinado período de tiempo dependerá de la naturaleza del producto y del público al que se dirige. Este número se ha visto afectado significativamente con los sistemas automáticos de llamadas que le reducen al operador el tiempo que pierde al realizar la llamada y cuando el teléfono al que se llama está ocupado. 


\section{Bajo costo en términos relativos.}

En programas de telemercadeo bien estructurados, el costo por contacto puede ser bajo. El costo de estas llamadas es bastante inferior al costo de la visita de un vendedor, pero mayor que el costo por contacto de un envío postal. (Telemarketing. La red como soporte de marketing y comunicación, 2007).

\section{Desventajas.}

De igual forma el autor José Manuel Alvares Sánchez hace referencia de que las campañas de telemercadeo al ser tan estrechas en la forma en la cual se ofrece, que a su vez dificulta y limita la efectividad de la misma, a continuación se muestran algunos de los principales aspectos por los cuales es poco provechoso utilizar las campañas de telemercadeo (Álvarez Sánchez, 2007).

\section{Selección de un público determinado:}

Se hace determinante para el desarrollo de esta técnica la selección del público al cual queremos dirigirnos, ya que no podemos abarcar una muestra de consumidores tan amplia como con otras de marketing.

\section{Existencia de una distancia espacial entre emisor y receptor:}

La eficacia del telemercadeo se ve muy disminuida cuando se utiliza como técnica de marketing y comunicación, ya que puede existir una gran distancia social y espacial entre el emisor del mensaje y sus recepciones. 


\section{Escaso nivel de vinculación:}

La interacción mantenida entre empresa y cliente potencial, de manera virtual, no es tan vinculante como la forma presencial, ya que un email o una conversación son más fáciles de olvidar (Álvarez Sánchez , 2007).

\section{Proceso de Telemercadeo.}

La elaboración de una campaña de telemercadeo requiere de la conformación de ciertos pasos a seguir que se replican en cualquier modelo o contexto incluyendo las campañas de telemercadeo para el sector bancario, de tal forma que esta conduzca a que se logre con el cometido de comunicar cierta información ya sea para obtener alguna otra, o para ofrecer servicios y productos. A continuación (Rafael Muñiz) da a conocer cómo es que se estructura el proceso de las campañas de telemercadeo de forma generalizada en 5 pasos los cuales son cíclicos, entendiendo que en el mercadeo es necesario identificar las necesidades de los clientes y según esto elaborar nuevos modelos de productos y servicios que satisfagan las necesidades de los clientes y cada vez logren fidelizarlos haciéndolos clientes potenciales (Rafael Muñiz, 2005).

\section{Conformación de campaña.}

"En esta primera etapa se formula la necesidad que se tiene en torno al producto o servicio que se pretende ofrecer, se detalla el medio de comunicación por el cual se va a ofrecer el producto, (Ya sea solo telefónico u otros) se modula lo que se pretende dar a conocer al cliente para así esquematizar el tipo de cliente o prospecto que se va a ofrecer. 


\section{Elaboración de Guion.}

En la segunda parte se elabora un guion de telemercadeo el cual va a usar como instrumento de trabajo para los tele operadores, este les permita seguir una secuencia del modo de conformar la llamada, buscando de que esta cumpla con los lineamientos y las exigencias tanto internas de la empresa como externas del gobierno y de la sociedad buscando entrar dentro de los estándares adecuados para poder ofrecer apropiadamente un producto o un servicio.

\section{Identificación de clientes potenciales.}

Como medida para focalizar el margen de mercado que se pretende ofrecer el producto, se lleva a cabo la elaboración del perfil del cliente o del prospecto el cual cumpla con los parámetros que permitan acceder al producto creado, es determinante que la segmentación del mercado y la focalización del público objetivo sea adecuada para que en su misma medida dictamine la diferencia en resultados positivos.

\section{Promoción Venta o Servicio.}

Lo que viene a continuación es la ejecución de la campaña de telemercadeo, cabe aclarar que esta puede llevar por medio de llamadas de salida o en su defecto por medio de llamadas de entrada esto depende directamente de la forma de la Campaña de telemercadeo inicial, ya que no únicamente se puede presentar que estas emerjan directamente desde el Call Center buscando nuevos prospecto o que los clientes o nuevos prospectos llamen para poder aclarar sus dudas y consolidar una compra, o esto se puede

presentar a la vez como se mencionó con anterioridad, depende directamente de la 
elaboración inicial de la campaña. En este proceso se mide la efectividad de las llamadas el número de respuestas, negativas, efectivas y los posibles prospectos.

\section{Seguimiento y Control.}

A continuación con los prospectos o los clientes que hayan quedado interesados en el producto o servicio ofrecido se le hace un seguimiento que les permita fortalecer su confianza con lo que van a adquirir y así consolidar como una llamada efectiva o no efectiva, de tal modo que lo que se está promoviendo es al seguimiento y control de cada una de las llamadas que se obtuvieron a su vez medir que tan satisfactorio fue la recepción por parte de los clientes lo ofrecido por la empresa." (Rafael Muñiz, 2005).

\section{Tipos de clientes en las campañas de telemercadeo.}

En el telemercadeo se identifican diversos perfiles que permiten reconocer la forma de cómo se cliente se siente en torno al ofrecimiento del producto o servicio por un medio telefónico, al no tener la posibilidad de visualizar al cliente, se puede llegar a identificar como es que este se expresa por medio del telefoneo con el operador, lo que a su vez mide la receptividad por parte del cliente para tomar el producto. A continuación la revista del Emprendedor en su artículo de (Rafael Muñiz, 2005, pág. 3) menciona los diversos tipos de clientes en una campaña de telemercadeo;

\section{"El desconfiado:}

Es intransigente, gira en torno a prejuicios, tiene unas ideas fijas y trata de dominar al interlocutor. Juan Carlos Alcaide conferencista de marketing con más de 15 años recomienda conservar la tranquilidad, respetar sus ideas y hacerle ver 
que valoramos su opinión, buscar puntos comunes y prestarle mucha atención. Al escéptico conviene abrumarle con todo tipo de informaciones, comentarios y documentación extra.

\section{El impulsivo:}

Cambia continuamente de opinión, es impaciente, superficial y suele interrumpir la argumentación. Debemos explicar de forma clara y segura, evitando dar muchos detalles. Expondremos las principales.

\section{El específico:}

Exigen detalles y pruebas concluyentes, buscan el corto plazo y les cuesta hacerse una imagen general. Conrad recomienda desglosar la propuesta en varios compromisos progresivos, para que no tengan que adoptar grandes decisiones al momento.

\section{El indeciso:}

Intenta aplazar la decisión mediante objeciones, evade el cierre y mantiene una postura defensiva. Alcaide propone la escucha paciente y comprensiva, el halago moderado de sus puntos de vista con el fin de infundirle confianza e insistir en las desventajas que tiene el aplazar la decisión.

\section{El versátil:}

Es aquel que siempre está haciendo mil cosas a la vez, pero deja los proyectos sin acabar. Conviene dejarle hablar y preguntar y ofrecerle de forma 
breve y clara todas las alternativas que hay a su disposición. Es importante hacerle un seguimiento posterior.

\section{El inmovilista:}

Le cuesta innovar, cambiar, y procura no pasar a una tarea nueva hasta que no ha acabado la anterior. En nuestra conversación debe primar sobre todo la secuencia lógica, cubriendo todas las etapas del camino punto por punto, apelando fundamentalmente a su sentido racional.

\section{El ególatra:}

Lo sabe todo, se muestra altivo y dominante y tiende a no respetar al otro. Prefiere la rentabilidad directa a cualquier otra variable. Según Alcaide, conviene elogiarle, llamarle por su nombre, utilizar expresiones suyas («es lo que usted plantea», «como usted ha dicho») y recabar su opinión de vez en cuando. La argumentación debe enfocarse hacia los beneficios inmediatos y hacia ventajas exclusivas" (Una llamada ganadora, 2005, pág. 3).

Las cinco faces que hacen parte del proceso consiste en evaluar aspectos que pueden llevar a que la campaña se ejecute de manera adecuada, dado que requiere de un análisis tanto de los productos que se piensan promocionar como la identificación de los clientes a los cuales va dirigida la campaña.

\section{Estructura básica de un guion de telemercadeo.}

Cuando se hace referencia a la estructura de un guion, se hace mención directamente al libreto con el cual la tele operador leerá para conducir la llamada con la cual se dirigirá al cliente 
y de esta manera hará que la llamada cumpla con su cometido. La conformación estructural y estética de cada guion de telemercadeo es vital, y esta puede variar según su objeto y según la organización la cual la lleve a cabo, desde la elaboración correcta de una esta estructura de un guion de telemercadeo no solo se está promocionando un producto o servicio sino que a su vez se trasmite en esencia lo que es la compañía (Misión, visión y filosofía) (Kazañetz, 2004).

El realizar un guion de telemercadeo requiere de amplio conocimiento en diversos aspectos puesto que tanto para empresas cotidianas como empresas financieras, se deben adaptar a las normas y a las regulaciones que se tangan por parte del gobierno que las regula y a su vez mantener entre los estándares de calidad y buen servicio que exige cualquier cliente a la empresa la cual le llama.

A continuación se muestra cómo se conforma una estructura básica de un guion de telemercadeo, la revista del Emprendedor en su artículo (Una llamada ganadora, 2005, pág. 2) detalla la conformación de este por medio de 4 pasos:

\section{Presentación:}

Una presentación formal en la que primero se presenta la compañía y después al propio vendedor, se reserva para la oferta de un servicio o un producto novedoso en el mercado y especialmente si se llama por primera vez. Una presentación cercana llevaría el orden inverso: primero se presenta el vendedor y después a la compañía. Este tipo es mejor para ofrecer productos más cotidianos (como por ejemplo los servicios telefónicos y de Internet) y la recurrente sería la destinada a los clientes habituales. 
En la presentación deben evitarse preguntas del tipo « ¿cómo está?», «¿qué tal le van las cosas?». Y expresiones de disculpa: «Siento molestarle en este momento». Las primeras fuerzan a una familiaridad que no corresponde con un potencial usuario y las segundas colocan al vendedor en una posición de humildad innecesaria. Lo que se debe perseguir en la presentación es crear un buen rapport, o como resume Armando Pérez "hay que buscar el buen rollo, crear una buena sintonía con el cliente a través de la empatía y de la sonrisa telefónica".

Mencionar la fuente de donde hemos obtenido el contacto puede interesar en algunos casos, pero no siempre. Cuando se trata de una llamada de empresa es una buena fórmula de apertura.

La última frase que hemos añadido en la presentación («¿podría ayudarme?/¿tiene un minuto»), es peligrosa, pero necesaria. Si responden afirmativamente allanan el camino, pero no hay que olvidar que una llamada telefónica casi siempre interrumpe una actividad y lo más probable es que el potencial cliente responda con un «no» tajante. Ante esta negativa, el vendedor debe tratar de concertar una nueva cita para más adelante, en un momento en que el interlocutor esté más relajado, con preguntas del tipo de «icuándo es un buen momento?» «¿Le parece bien que le llame más tarde?» «Dígame una hora a la que pueda volver a llamarle». Si el interlocutor persiste en su negativa, lo mejor es olvidarse de él y pasar a otro contacto. Si responde con un «depende, ¿de qué se trata?», hay que seguir adelante. Jay Conrad Levinson, en su libro Televenta de guerrilla, recomienda incluso reconocer que se está realizando una llamada para vender algo. 


\section{Sondear al cliente.}

«Antes de presentarle en detalle el producto me gustaría hacerle cuatro o cinco preguntas. ¿Tiene usted seguro? ¿Qué coberturas tiene? ¿Está contento con su actual compañía? ¿Qué es lo mejor de su actual proveedor y qué es lo peor? ¿Qué prestaciones le gustaría cambiar? ¿Qué gestiones desearía que fuesen más fáciles?»

Se trata de identificar las necesidades del cliente según las motivaciones de compra. Hay poco nuevo que inventar pues la mayoría de profesionales tiene preguntas tipo de cuyas respuestas se deducen los móviles de compra del interlocutor. Esta fase no debe descuidarse.

En este estadio se debe desarrollar al máximo la escucha activa, es el momento de sonsacar toda la información posible del cliente.

Armando Pérez insiste en que se trata de "identificar la necesidad explícita, propulsora de una satisfacción, que pueda encajar con los atributos de nuestros productos. Se trata de conseguir que el cliente tenga ganas de comprar ese producto que cubrirá sus expectativas". Conviene tomar notas para utilizar los datos más adelante.

\section{Rebatir objeciones.}

«Nuestro seguro resulta aparentemente más caro que el de nuestros competidores, pero le garantizo que es una inversión rentable que le ofrece más garantías y coberturas que una simple póliza. Además, cuenta con el respaldo de una compañía con 30 años de antigüedad». 
Es fundamental que el departamento de marketing y el de producto dejen claros los aspectos diferenciadores del producto, para qué se ha diseñado y cómo sacar partido a las objeciones y móviles de compra para tener una batería de réplicas preparadas antes de la conversación.

Tampoco está de más preparar, junto a las ventajas que obtendrá nuestro cliente, una lista de las desventajas de no hacerlo. Rebatir las previsibles objeciones antes de que el cliente las plantee es una buena táctica.

Hay que tratar de dar un valor añadido, como se asegura en el libro Televenta de guerrilla: a igual calidad de producto, el cliente se decanta por el de menos precio. El guerrillero ofrecerá algo más del producto.

Como insiste Pérez, “es necesario reducir el Temor, la Incertidumbre o la Duda las 'TID'- en la interacción. En el momento en que quede alguno de esos sentimientos sin aclarar, la compra se pierde y el proceso se identificará con esos miedos para darles la vuelta y 'educar' al cliente".

\section{Cierre.}

«Si está de acuerdo sr. Hernández, lo que podríamos hacer ahora sería tratar de encontrar un hueco para vernos. ¿Qué le parece el día 12, a las 17.00 horas?» «Si está de acuerdo, sr. Ruiz, esta misma tarde le envío por correo/fax toda la documentación/los papeles que se necesitan para que pueda firmarlos».

El momento crucial de la venta telefónica. Para Armando Pérez, "el cierre es como una brújula, solamente se debe utilizar cuando uno está perdido y ya no sabe por 
dónde salir. Si todo lo anterior se ha hecho bien, el cierre viene solo. Hay que saber concluir un proceso en el que hemos conseguido que el cliente tenga ganas de comprar y de esta manera si todo lo anterior ha funcionado casi siempre el cierre es una invitación del cliente: «Entonces, ¿qué tengo que hacer? ¿Cómo lo puedo comprar?»

Es importante que la venta se produzca 'hoy', es decir, en el momento de la llamada telefónica o, si no es posible, dejar emplazado y cerrado el encuentro o la llamada de confirmación. Para ello, se puede recurrir a ofertas o promociones especiales que vencen en la fecha de la llamada o en los días siguientes.

Y siempre dejar que sea el cliente el que cuelgue primero.

(Una llamada ganadora, 2005, pág. 2).

\section{Segmentación de bases de datos en CRM.}

La minería de datos es determinante en una campaña de Tele mercadeo, puesto que la adecuada optimización y segmentación de bases de datos permite perfilar y perfeccionar nuevos prospectos y dar con los clientes que demandan los productos o servicios, es por ello que la información recolectada por parte de los clientes debe quedar almacenada en una base de datos que facilite su segmentación y sea eficaz (Álvarez Sánchez, 2007)

El éxito o el fracaso de una campaña de tele mercadeo se puede ver en la correcta depuraciones la base de datos del CRM, cabe aclarar que por más de que se tanga una vasta cantidad de información almacenada en bases de datos, no es nada eficiente de que este recurso 
no se optimiza para poder ofrecer los productos o servicios al mercado adecuado. (CRM: Tres estrategias de éxito, 2004).

La oferta que tenga la empresa para dar al mercado debe cumplir un perfil específico de clientes o prospectos, es por eso que para poder moldear a ese segmento de mercado se debe analizar a profundidad al tipo de cliente al cual se le desea ofrecer un producto por medio de una campaña de tele mercadeo, de tal forma que desde el inicio se hace indispensable cavar la información del cliente para así conocer a fondo las necesidades del mismo, con el fin de que se pueda brindar el producto o servicio deseado (Plan de negocios para crear una empresa de servicios de CRM, 2008).

Uno de los elementos más destacados en el momento de solicitar información a los clientes es obtener la información certera y adecuada que permita en un futuro segmentar las bases de tele mercadeo según un nicho de mercado específico. (CRM: Tres estrategias de éxito, 2004).

\section{Tipo de información general que se debe indexar en la base de datos.}

1. Nombres y apellidos de las personas,

2. Dirección de residencia,

3. Número telefónico,

4. Correo electrónico,

5. Fuente de origen del nombre,

6. Fecha en que fue incorporado,

7. Historia de compra (productos, fechas, volúmenes),

8. Datos demográficos (edad, sexo, ingreso, educación), 
9. Información miscelánea (presencia de niños en el hogar, casa arrendada o propia, talla de ropa, etcétera).

(Cava, 2004)

\section{Marco Normativo}

En Colombia con la llegada de las campañas de telemercadeo hechas por los Contact Center, se vio la necesidad de aclarar constitucional y normativamente cómo actuarían estas dentro de un marco legislativo, puesto que para el año 2005 se venían presentando conflictos normativos en torno a las acciones que estas llevaban a cabo continuamente a diversas personas.

Por tal motivo en el año 2014 se formalizo el decreto 1499 del 12 de Agosto de 2014 por el cual se "reglamentan las ventas que utilizan métodos no tradicionales y las ventas a distancia" (Ministerio de Comercio, 2014) este decreto se encargó de regular desde entonces las llamadas que se realizan en los Contact Center.

A continuación se mencionan algunos de los artículos más prominentes que involucran el desarrollo de las campañas de telemercadeo en Colombia.

Artículo 4. Ventas no tradicionales por abordaje intempestivo. Se considera que existió una venta no tradicional por abordaje intempestivo cuando, sin ser propiciado por el consumidor, el primer contacto entre este y el vendedor se da por fuera del establecimiento de comercio, aun cuando la operación se concluya en el establecimiento de comercio del vendedor o en instalación provisional o temporal acondicionada para el efecto. (Ministerio de Comercio, 2014, pág. 2) 
En estos términos, se consideran ventas no tradicionales por abordaje intempestivo, entre otras situaciones, aquellas en las que el consumidor es abordado en espacios públicos abiertos o en corredores o lugares de desplazamiento público de instalaciones comerciales o institucionales, o las que usualmente ocurren para la venta de colecciones de libros o enciclopedias, revistas, suscripciones, cursos o materiales para el aprendizaje de idiomas, tiempos compartidos, planes vacacionales o de turismo, seguros, planes funerarios, acciones de clubes, afiliaciones a gimnasios, entre otros (Ministerio de Comercio, 2014, pág. 3).

Artículo 6. Ventas a distancia. De acuerdo con lo establecido en el numeral 16 del artículo 5 de la Ley 1480 de 2011, se consideran ventas a distancia las realizadas sin que el consumidor tenga contacto directo con el producto que adquiere, a través de correo, teléfono, catálogo, comercio electrónico o con la utilización de cualquier otra técnica de comunicación a distancia. (Ministerio de Comercio, 2014, pág. 3)

Artículo 7. Responsabilidad. Para efectos del presente decreto, se entenderá que las obligaciones previstas en los numerales 3 y 4 del artículo 46 de la Ley 1480 de 2011, son exigibles exclusivamente a quien realiza la operación de venta en forma directa al consumidor. Sin perjuicio de lo anterior, el productor es responsable del cumplimiento de dichas obligaciones, cuando un tercero realiza la operación de venta en su nombre y representación. (Ministerio de Comercio, 2014, pág. 3)

Respecto de las obligaciones previstas en los numerales 1 y 2 del artículo 46 de la Ley 1480 de 2011, en lo que tiene que ver con la entrega del bien o servicio y la, posibilidad de presentar reclamaciones y solicitar devoluciones, el productor y el proveedor serán 
solidariamente responsables, de conformidad con los artículos 10 y 11 de la misma ley. (Ministerio de Comercio, 2014, pág. 3)

Artículo 8. Información previa que el vendedor debe suministrar al consumidor en las transacciones de ventas a través de métodos no tradicionales o a distancia. Sin perjuicio de lo previsto en los artículos 23, 24 Y 37 de la Ley 1480 de 2011, en las ventas por métodos no tradicionales o a distancia, el vendedor, con anterioridad a la aceptación de la oferta, debe suministrar al consumidor como mínimo la siguiente información:

1. Su identidad e información de contacto;

2. Características esenciales del producto;

3. El precio, conforme con las reglas previstas en el artículo 26 de la Ley 1480 de 2011

4. Los gastos de entrega y transporte, cuando corresponda;

5. Las formas de pago que se pueden utilizar;

6. Las modalidades de entrega del bien o prestación del servicio;

7. La disponibilidad del producto;

8. La fecha de entrega o de inicio de la prestación del servicio, cuando corresponda;

9. La existencia del derecho de retracto previsto en el artículo 47 de la Ley 1480 de 2011;

10. La existencia del derecho a la reversión del pago en los casos previstos en el artículo 51 de la Ley 1480 de 2011;

11. El plazo de validez de la oferta y del precio; 
12. Las cláusulas y condiciones relativas a renovación automática o permanencia mínima, ésta última en caso de que proceda en los términos del artículo 41 de la Ley 1480 de 2011.

Artículo 9. Contenido mínimo de los contratos de ventas que utilizan métodos no tradicionales o a distancia. Sin perjuicio de lo dispuesto en la Ley 1480 de 2011, los contratos de ventas no tradicionales o a distancia deberán incorporar como mínimo las siguientes condiciones:

1. Identidad del vendedor y su información de contacto;

2. Características esenciales del producto;

3. El precio, conforme con las reglas previstas en el artículo 26 de la Ley 1480 de 2011.

4. Los gastos de entrega y transporte, cuando corresponda;

5. Las formas de pago que se pueden utilizar;

6. Las modalidades de entrega del bien o prestación del servicio;

7. La fecha de entrega o de inicio de la prestación del servicio, cuando corresponda. Salvo pacto en contrario, el vendedor deberá entregar el bien o iniciar la prestación del servicio a más tardar en el plazo de treinta (30) días calendario contados a partir de la celebración del contrato; 
8. Información suficiente sobre las condiciones y modalidades de ejercicio de los derechos de retracto y reversión del pago, de acuerdo con lo establecido en los artículos 47 y 51 de la Ley 1480 de 2011;

9. La identificación e información de contacto del prestador de los servicios postventa, así como la forma de acceder a dichos servicios;

(Ministerio de Comercio, 2014, pág. 4)

La normatividad es de importancia para las campañas de telemercadeo, para que estas se articulen en cuanto a la reglamentación emitida por el gobierno colombiano, que busca encaminar una correcta ejecución de una campaña, y que esto sirva para que tanto personas como organizaciones se beneficien, de manera tal que aspectos como la información no trasciendan más allá del uso permitido, y además sirvan como marco de confianza para las personas. 


\section{CAPITULO III}

\section{Diseño metodológico.}

Para la elaboración de la investigación del impacto de las campañas de telemercadeo se concibe por la ejecución de un modelo cualitativo, llevado a cabo por un cuestionario permita cualificar la opinión de según un grupo de expertos en campañas de telemercadeo el en el sector bancario, de forma que se evalúen los principales aspectos que permitan establecer el impacto de las campañas de telemercadeo de las entidades del sector bancario, para la captación de nuevos clientes. De modo tal que a continuación se esbozara y se presentará la manera en la que se ejecutara este instrumento que permitirá comprobar el objeto de investigación y revelar los resultados de esta investigación.

\section{Método cualitativo.}

Para determinar los factores que se pretenden evaluar en la elaboración de este estudio cualitativos citamos a (Weber, (1864-1920)), quien menciona que el método cualitativo se utiliza para la recolección de datos y así probar hipótesis con base en la medición numérica y el análisis estadístico, para establecer pautas de comportamiento y probar teorías (Metodologia de la Investigacion, pág. 6). De acuerdo a lo anteriormente expuesto, se tomara la información recolectada y se hallaran los principales aspectos que permitan evaluar el impacto de las campañas de telemercadeo de ventas en el sector bancario en Colombia, con el objeto de poder medir la opinión puntual frente estos que requieren atención que permita cualificar cómo es que este se encuentra este en la en la actualidad en razón de la captación de clientes.

De forma tal que el modelo que se aplicara para poder estructurar el instrumento cualitativo de investigación será un cuestionario, que permitirá acercarse a la medición del 
impacto del asunto en mención, a continuación se explicaran los diversos elementos necesarios que se aplicaran dentro del cuestionario para poder con determinar con exactitud cuáles son los factores más determinantes que promueven el éxito o el fracaso de las mismas.

\begin{abstract}
Alcance.
El alcance de la investigación se orientó hacia un enfoque de estudio descriptivo que según el libro de (Metodologia de la Investigacion) "que lo que busca es especificar propiedades y características importantes de cualquier fenómeno que se analice" (pág. 92), de tal forma que durante el trascurso de la investigación fue detallar las principales propiedades y las características del telemercadeo, y en torno a estas examinar los aspectos más destacados de la misma para así poder elaborar el instrumento, de modo tal que estos elementos se utilicen para que los especialistas del telemercadeo del sector bancario determinen según su conocimiento sobre el aspecto a evaluar, según las principales características y aspectos que componen las campañas de telemercadeo si se ajustan con la investigación metodológica elaborada en la evaluación del impacto de las campañas de telemercadeo.
\end{abstract}

\title{
Muestra de investigación.
}

La herramienta que se aplicara en este de este estudio, es de muestra no probabilística, se entiende que esta muestra será tomada de según las causas relacionadas con las características de la investigación o los propósitos del investigador (Johnson, 2014, Hernández-Sampieri et al., 2013 y Battaglia, 2008b). Lo sean casos representativamente exactos dentro de una población que sea dirigida, ya sea grupo o subgrupo, sino que lo que se busca es que cumplan con ciertas características que el estudio busca evaluar los principales aspectos que permiten establecer el 
impacto de las campañas de telemercadeo de las entidades del sector bancario para la captación de nuevos clientes. (Metodología de la investigación, 2014).

Para que los resultados del estudio sean más acertados en torno a la investigación, es necesario focalizar el grupo que cumpla con las características de expertos en telemercadeo, para ello se aplicara un "método de muestreo en cadena o por redes", que comprende el momento en el que "se identifica a una persona que cumpla con un perfil en específico, quien a su vez suministrara el contacto de otra persona con un perfil similar para incluirlo dentro de la muestra para el estudio en mención, puesto que esta persona cuenta con los conocimientos requeridos, y así sucesivamente" (Metodología de la investigación, 2014, pág. 485).

Por tal motivo y como primera medida, a continuación se presentara el grupo de enfoque no probabilístico al que se le aplicara el estudio de investigación que será contactado o determinados por un modelo de muestreo por redes o en cadena.

\section{Características:}

El grupo de enfoque que se seleccionó para poder aplicar el cuestionario es a personas especializadas, o que en cierta medida se involucren en la operación de un servicio de campañas de telemercadeo. Al tratarse este estudio del sector bancario, se procurara que los especialistas sean personas que laboren en este, para que la muestra y el resultado sea fiel con el estudio, se toma una muestra de (20) de personas las cuales se le aplicara el cuestionario buscando que se midan los factores que más se destacan en torno al impacto de las campañas de telemercadeo de ventas en el sector bancario.

- Género: Masculino o Femenino

- Edad: Entre 30 y 45 años 
- Perfil laboral: Especialistas en el sector bancario

- Estado Civil: Casado, Soltero, Divorciado, Viudo

- Estrato: 3, 4, 5 y 6

- Estudios: Profesional universitario y/o especializado

El cuestionario cualitativo se aplicara a especialistas de telemercadeo del sector bancario, el cual estará basado en, "Un cuestionario como instrumento de recogida de datos cualitativos", que estará adaptado al contexto de la investigación, que a su la vez permita determinar el impacto de las campañas de telemercadeo (Hernández Sampieri, Fernández Collado, \& Baptista Lucio, 2014). Buscando evaluar los principales aspectos en la captación de nuevos clientes.

\section{Cuestionario.}

Lo primero que se observa es que un cuestionario es un instrumento que se usa como herramienta de investigación el cual consiste en una serie de preguntas escritas, las cuales están conformadas de manera lógica con el fin de tener información relevante en torno a una cuestión en específico, cabe aclarar que para la implementación de un cuestionario como modelo de investigación, debe moldearse al tema en concreto que en este caso es saber cuál es el impacto de las campañas de telemercadeo en el sector bancario, esta serie de preguntas permitirá definir de manera precisa el propósito de esta investigación. (Chasteauneuf, 2009). Que de igual forma “debe ser congruente con el planteamiento del problema e hipótesis" (Brace, 2013). Este modelo de cuestionario se planteara bajo diversas premisas de investigación que permite obtener la información deseada.

En la realización del cuestionario como instrumento de investigación y de evaluación, se realizaran preguntas cerradas y de opción múltiple, lo que le permitirá al encuestado poder 
escoger o ponderar las opciones más predilectas para él, en este orden de ideas, las preguntas tendrán como objeto que los “especialistas de mercadeo" determinen y cualifiquen su opinión en torno al impacto de las campañas de telemercadeo en el sector bancario. En efecto serán preguntas "directas" que le permitirán al encuestado focalizarse puntualmente en el tema que se está evaluando, veamos a continuación como es que se va a implementar el cuestionario en el evaluar el impacto de las campañas de telemercadeo.

\section{Escalamiento Likert.}

El método utilizado para poder cualificar el impacto de las campañas de telemercadeo en la elaboración de las respuestas es el escalamiento de Likert, este método consiste en un enfoque de en la cual se arrojan una serie de afirmaciones o juicios en la estructura de sus preguntas y luego se le solicita al evaluador que a cada afirmación que se expone en el enunciado emita un juicio personal según su conocimiento en causa, donde emita su opinión por medio de una escala de calificación en donde por medio de una escala del 1 al 5 se califique su actitud en torno a la afirmación en contexto, se solicita al sujeto que externe su reacción eligiendo uno de los cinco puntos o categorías de la escala, siendo 1 completamente en desacuerdo y 5 totalmente de acuerdo. (Likert, 1932)

De tal modo que la sumatoria de la calificación del enfoque de investigación se podrá cualificar de manera precisa en torno a las diversas variables que se evalúan por medio del cuestionario. Las afirmaciones miden el grado de aceptación o negación que emite un juicio en concreto que permite acercarnos cada vez más al objeto de investigación que en este caso es el impacto de las campañas de telemercadeo en el sector Bancario. 
A continuación se darán a conocer algunas de las estructuras empleadas en las respuestas cerradas que se aplicaran en el cuestionario que podrán moldear y asemejar la calificación.

\author{
Muy de acuerdo \\ De acuerdo \\ Ni de acuerdo ni en desacuerdo \\ En desacuerdo \\ Muy en desacuerdo
}

\title{
Siempre
}

La mayoría de veces si

Algunas veces si algunas veces no

La mayoría de veces no

Nunca

Completamente verdadero

Verdadero

$\mathrm{Ni}$ falso ni verdadero

Falso

Completamente falso

Totalmente de acuerdo

En desacuerdo

Neutral

En desacuerdo

Totalmente desacuerdo

El escalamiento Likert permitirá valorar el grado de aceptación o negación de la afirmación en mención, de manera tal, que al ser una escala aditiva lo que se realizara a continuación es sumar y ponderar variables evaluadas, proporcionándoles un valor de calificación que permita medir efectivamente el impacto de las campañas de telemercadeo, en este sentido que si la evaluación es negativa se le dará una calificación de (1) la siendo esta la más baja y si la respuesta dada es positiva se le dará una valoración de (5) siendo esta la más alta. 
Lo que arrojara como resultado de cada una de las afirmaciones se sumara según el número de encuestados, que en este caso son 20 especialistas la suma y ponderación de la misma mostrará grado real de aceptación de lo que se evalúa en la afirmación.

\section{Tipo de enfoque del instrumento.}

El resultado que se puede obtener por la formulación de una pregunta puede llegar a ser abierta o cerrada, este depende directamente de la correlación de la pregunta que emite dentro de su estructura, de tal modo que para la implementación del cuestionario se va aplicar el tipo de preguntas cerradas, las cuales contienen categorías u opciones que han sido previamente delimitadas y que su vez arrojaran una serie de respuestas concretas, lo que permitirá cuantificarlas y obtener un resultado cualitativo de las mismas y a su vez nos facilitara su interpretación.

El primer método que se aplicara en la elaboración de preguntas del cuestionario son preguntas dicotómicas (Arroja dos posibles respuestas), que a su vez se incluirán preguntas con respuesta múltiples, las cuales mostraran su grado de afinidad con la respuesta seleccionada en un conjunto de opciones ya sea a favor o en contra (Hernández Sampieri, Fernández Collado, \& Baptista Lucio, 2014).

\section{Método de investigación en acción.}

Para abordar el estudio de las campañas de telemercadeo, se realizaron 3 faces, la primera de estas fue la observación, debido a labores en un escenario donde se lleva a cabo el telemercadeo, donde se ofrecen productos y servicios a clientes del banco y a personas externas, se pudo observar que tan determinante es una campaña de telemercadeo y su impacto en cuanto 
al entorno empresarial. De modo que lo que se realizó fue sintetizar el problema o la situación que se presentaba, por lo cual se comenzó a indagar y obtener información con respecto al asunto mencionado.

La segunda fase fue comprender, analizar e interpretar la información recolectada, de tal manera que se entienda la dimensión del problema, y así encontrar una solución que resuelva el problema inicial, factor que hace parte de la fase 3, y que permita de esta manera mejorar la situación del entorno hasta que esté completamente resuelto. (Stringer, 1999).

Los pasos mencionados se modelan en el siguiente gráfico 1 donde dan a conocer las 3 etapas;

- "Formulación de un plan o programa para resolver el problema o introducir el cambio.

- Implementar el plan o programa y evaluar resultados.

- Realimentación, la cual conduce a un nuevo diagnóstico y a una nueva espiral de reflexión y acción.” (Metodología de la investigación, 2014, pág. 497).

Figura 1 Principales acciones para llevar a cabo la investigación-acción.

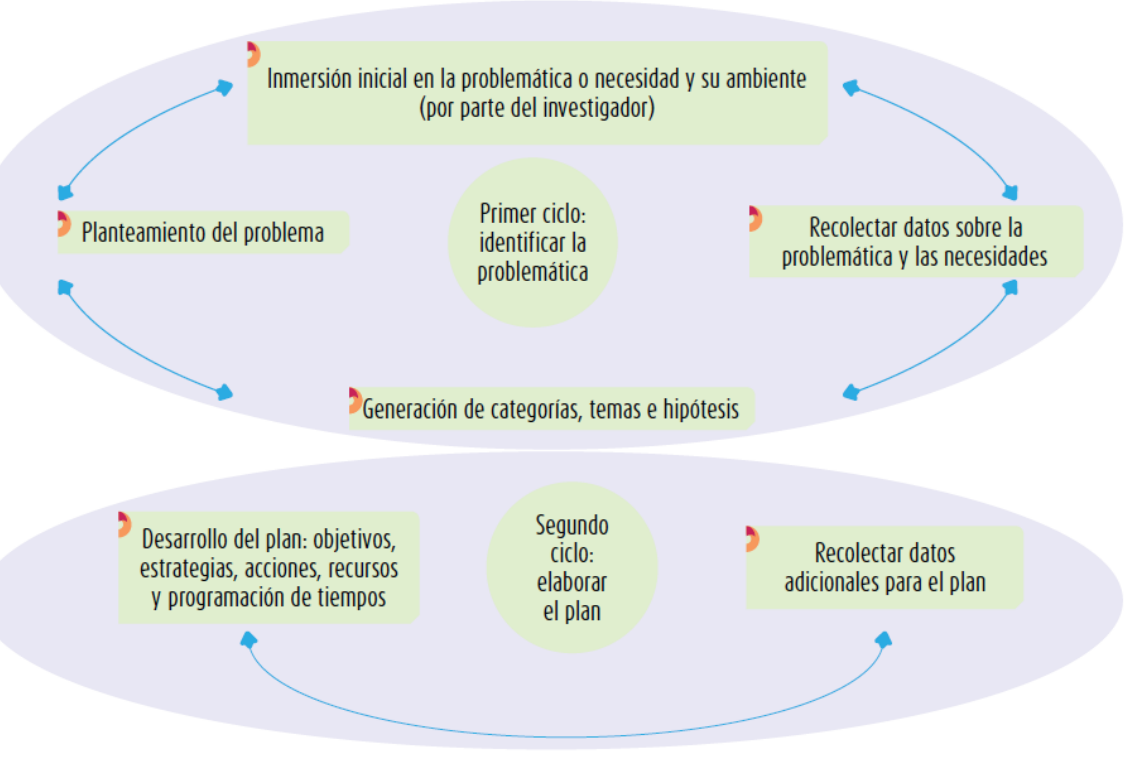




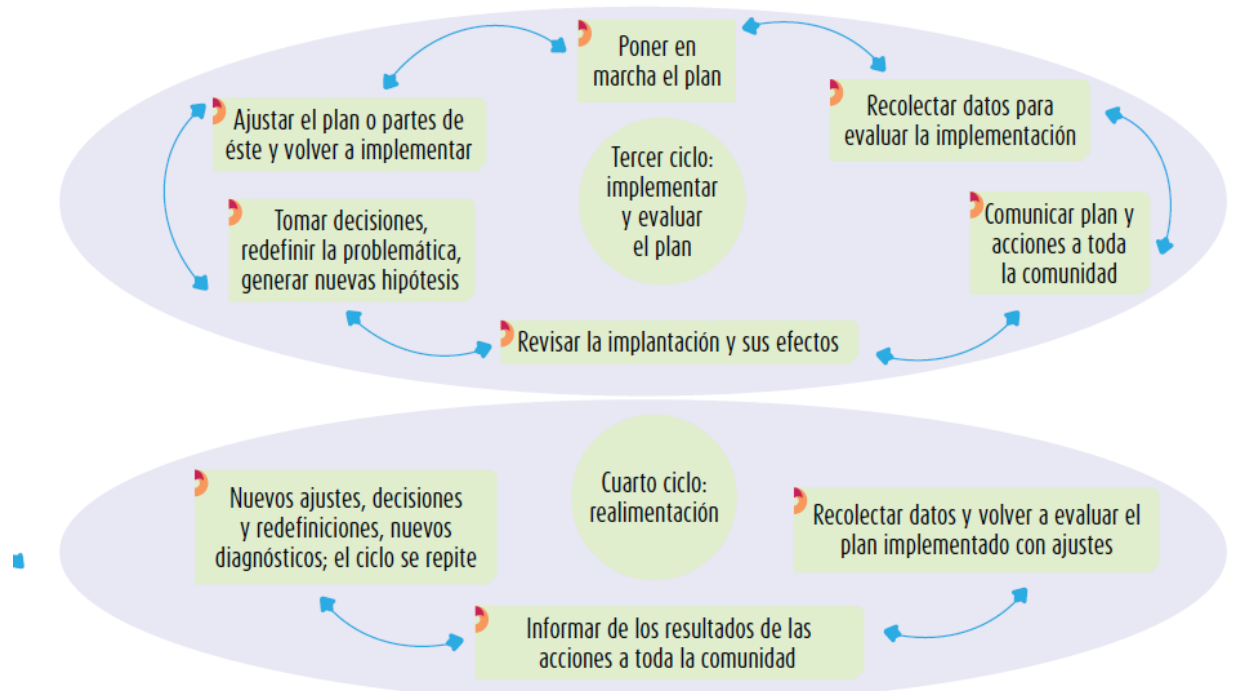

Fuente: (Metodología de la investigación, 2014, pág. 498)

\section{Metodología utilizada del proceso cualitativo.}

El modelo utilizado para esta investigación fue un proceso cualitativo, de donde se tomó una aproximación del grafico que se muestra a continuación lo que facilita y orienta la investigación hacia un estudio y a unos resultados completamente cualitativos, este proceso que se muestra se continuación, se llevó a cabo paso a paso para lograr obtener el resultado esperado, la gráfica de resumen de "Método en acción utilizando el Proceso cualitativo" forma una muy clara especificación del paso a paso que se incorporó en el estudio de las campañas de telemercadeo, como consiguiente se explicara de forma puntual como fue que este se aplicó en el estudio. 
Figura 2 Método en acción utilizando el Proceso cualitativo.

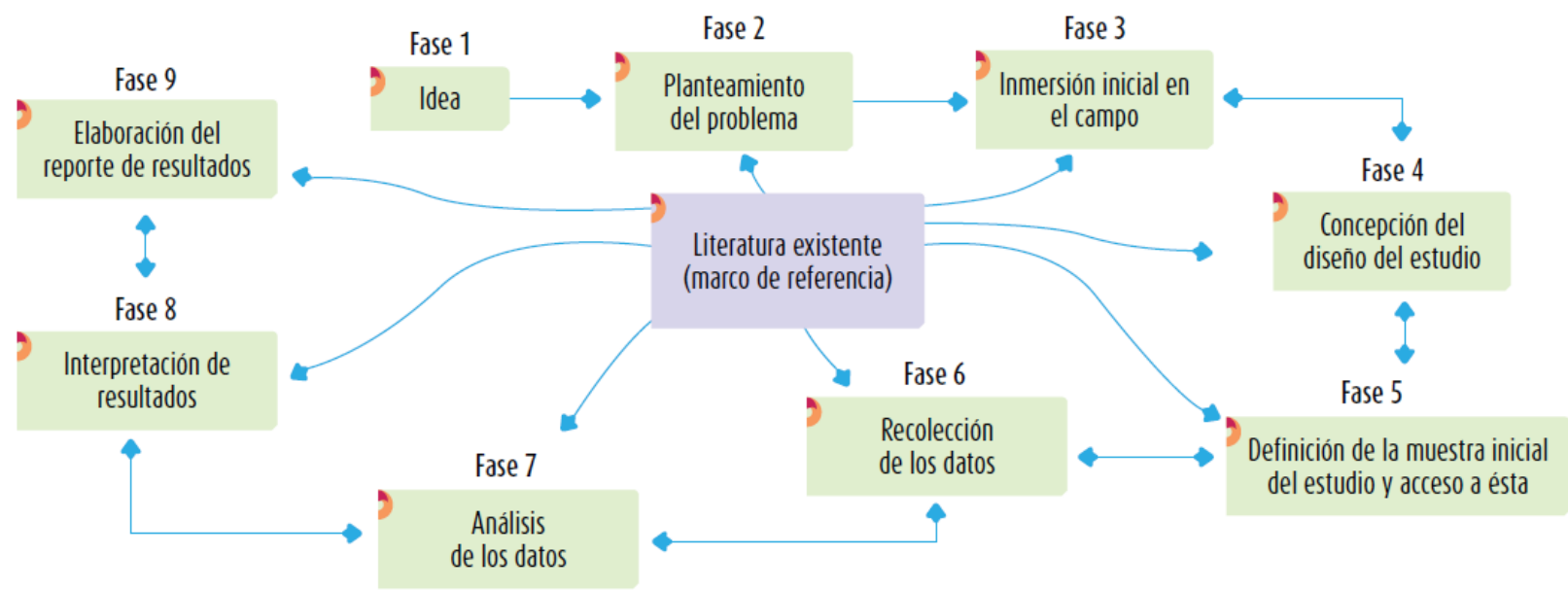

Fuente: (Metodología de la investigación, 2014)

Este está conformado por una serie de pasos que lo que buscan es facilitar la apropiación de la investigación, por medio de le ejecución estructurada de un método efectivo, que está basado en los modelos cualitativos que se han realizado con anterioridad. Hay una serie de fases que se explicaran como fue que estas se apropiaron en el desarrollo de este estudio para hacer el debido desarrollo de esta investigación monográfica.

\section{Fase 1: Idea}

Lo primero fue plantear la idea de lo que se pretendía abordar en el trabajo, por lo cual fue necesario realizar de lluvia de ideas, por tal motivo de la multiplicidad de temas se seleccionó el telemercadeo, y fue sobre ese este que se comenzó a ramificar, en razón a poder puntualizarlo y direccionarlo hacia un tema específico, partiendo de esto comenzaría el planteamiento del problema. 


\section{Fase 2: Planteamiento del problema.}

El punto de partida del trabajo fue el telemercadeo, por lo que se procedió a examinar cuales eran las principales dificultades que se presentaban dentro de las campañas de telemercadeo, y establecerlo como foco principal del estudio que se evaluara para comprender que fenómeno era el que se estaba presentando.

\section{Fase 3: Revisión de la literatura y desarrollo del marco teórico.}

Después se procedió a la investigación literaria, la cual conforma el marco teórico, que tiene como fin soportar el estudio en mención, se llevó a cabo por medio de diversos autores que con anterioridad habían hablado del uso de las campañas de telemercadeo, y a su vez se apoyó de diversos estudios de la academia que soportaban que era lo que se había estudiado.

\section{Fase 4: visualización del alcance del estudio.}

A continuación, fue determinar el alcance del estudio, que según el enfoque descriptivo, se focalizo en la descripción de las propiedades y de las características del mismo, con el fin de direccionar hacia donde se desarrollaría la investigación de lo que se pretendía evaluar que es el estudio de las campañas de telemercadeo en el sector bancario.

\section{Fase 5: Elaboración de hipótesis y definición de las variables.}

La elaboración de la hipótesis y la definición de las principales variables que se pretendían medir en el estudio de las campañas de telemercadeo se basó en las principales herramientas que lo conforman, y así identificar y medir el impacto de las campañas de 
telemercadeo, motivo por el cual fue necesario moldear los principales cuestionamientos basados principalmente en la hipótesis del mismo.

\section{Fase 6: Desarrollo del diseño de investigación.}

Lo siguiente en la elaboración del estudio, fue necesario crear un esquema de lo que se pretendía evaluar dentro de la investigación, motivo por el cual se diseñó una herramienta que en este caso, fue un cuestionario, que permitiera efectuar una evaluación a las campañas de telemercadeo en el sector bancario, a su vez se delimito la estructura de la herramienta a utilizar, debido a la mezcla de métodos cualitativos se decidió tomar como referencia a autores como Elliott, Brydon-Miller y Stringer que han comprobado la efectividad de los mismos, para que de esta manera la herramienta utilizada fuera más veraz para evaluar el impacto de las campañas de telemercadeo.

\section{Fase 7: Definición y selección de muestra.}

Teniendo el cuestionario en mención, se delimito la muestra, la cual mediría los principales factores que se pretendían evaluar, siendo un estudio directamente enfocado hacia las campañas de telemercadeo del sector bancario, por razones evidentes al estudio en relación se decidió seleccionar a personas especializadas en campañas de telemercadeo, involucradas en la operación y ejecución de las mismas en el sector bancario, que contaran con los conocimientos y con la experticia en el tema para que fuese más exacta la obtención de la muestra y de igual forma de sus resultados. 


\section{Fase 8: Recolección de los datos.}

Lo siguiente fue aplicar en la muestra seleccionada el cuestionario elaborado, a las personas que contaran con el perfil se les hizo una breve contextualización de lo que trataba el estudio, para que de igual forma facilitara el desarrollo del cuestionario, lo siguiente fue que cada uno desarrollo este cuestionario de manera autónoma e independiente para que se reflejara los conocimientos de la misma en el desarrollo del cuestionario.

\section{Fase 9: Análisis de los datos.}

Una vez los cuestionarios fueran completados, se continuo con la cuantificación de los resultados y de ponderación de los mismos, para que pasaran a ser de unos datos meramente cuantitativos a unos datos cualitativos, que permitieran evaluar el impacto que tienen las campañas de telemercadeo en el sector haciendo mención a las principales propiedades y características que lo conforman.

\section{Fase 10: Elaboración del reporte de resultados.}

Se culminó con el análisis de los resultados obtenidos, que tiene como objetivo la aclaración de los factores más evidentes para los entrevistados y determinar el impacto las campañas de telemercadeo en el sector bancario delimitando las principales propiedades y las principales características de las mismas. 


\section{CAPITULO IV}

\section{Análisis de resultados.}

\section{Gráfico y conteo de resultados.}

\section{Pregunta 1}

De las siguientes definiciones cual considera usted que se identifica a la definición de campaña telemercadeo, siendo 1 el más importante y el 4 el menos relevante. 


\section{Gráfica 3 de respuestas pregunta 1.}

De las siguientes definiciones cual considera usted que se identifica a la definición de campaña telemercadeo, siendo 1 el más importante y el 4 el menos relevante

Es el uso de diversos medios de comunicación como ( Mail , Teléfono, Celular, Mensajes de texto que sirven para poder obtener un acercamiento directo con el cliente

Es un medio de comunicación directo que usa como herramienta principal el teléfono para establecer una comunicación directa entre la empresa y el cliente

El telemercadeo se encuentra dentro de la categoría de ventas personales que va al cliente.

El uso innovador de equipos y sistemas de telecomunicaciones.

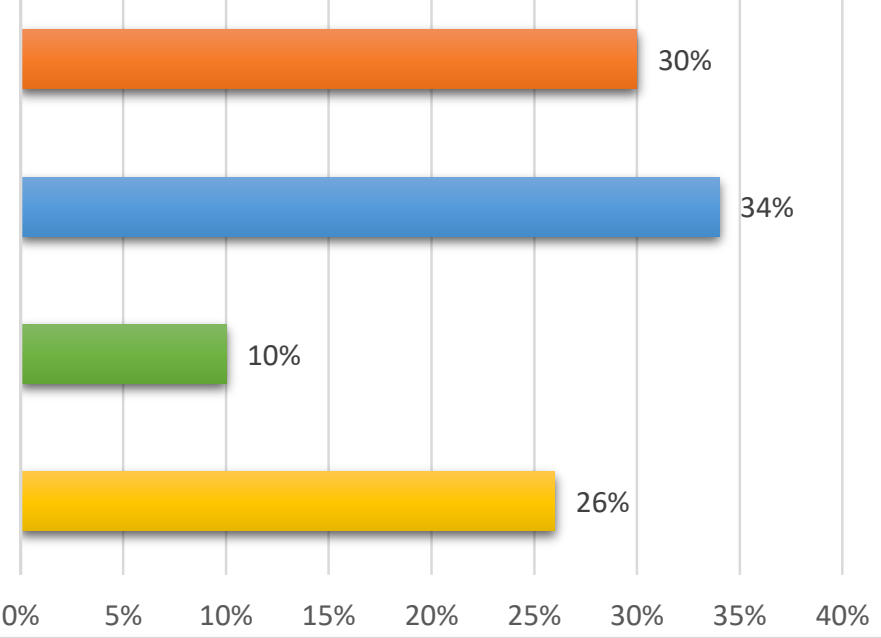

Fuente: Elaboración propia

\section{Pregunta 2}

Coloque en el orden de relevancia cuales son los principales usos de las campañas de telemercadeo, siendo 1 el más importante y 8 el menos importante.

Tabla Número 1: Respuestas Expertos

\begin{tabular}{|c|c|c|c|c|c|c|c|c|c|c|c|}
\hline $\mathbf{A}$ & $\begin{array}{l}\text { Entablar un encuentro } \\
\text { personal }\end{array}$ & $\mathbf{0}$ & $\mathbf{0}$ & $\mathbf{0}$ & $\mathbf{0}$ & $\mathbf{0}$ & 3 & 6 & 3 & 12 & $2 \%$ \\
\hline $\mathbf{B}$ & Investigación de mercado & 0 & 0 & 0 & 0 & 28 & 6 & 4 & 1 & 39 & $5 \%$ \\
\hline $\mathbf{C}$ & $\begin{array}{l}\text { Seguimiento y control de } \\
\text { productos y servicios }\end{array}$ & 48 & 49 & 36 & 25 & 12 & 0 & 0 & 0 & 170 & $24 \%$ \\
\hline D & Benchmarking & 0 & 0 & 0 & 10 & 12 & 9 & 6 & 2 & 39 & $5 \%$ \\
\hline $\mathbf{E}$ & $\begin{array}{l}\text { Comercializar bienes y } \\
\text { servicios }\end{array}$ & 112 & 77 & 36 & 20 & 0 & 0 & 0 & 0 & 245 & $34 \%$ \\
\hline
\end{tabular}




\begin{tabular}{|c|l|c|c|c|c|c|c|c|c|c|c|}
\hline F & Quejas y sugerencias & 0 & 0 & 0 & 5 & 28 & 21 & 24 & 14 & 92 & $13 \%$ \\
\hline G & Atención al cliente & 0 & 14 & 48 & 40 & 0 & 21 & 0 & 0 & 123 & $17 \%$ \\
\hline & & 160 & 140 & 120 & 100 & 80 & 60 & 40 & 20 & 720 & \\
\hline
\end{tabular}

Gráfica 4 de respuestas pregunta 2

Coloque en el orden de relevancia cuales son los principales usos de las campañas de telemercadeo, siendo 1 el más importante y 8 el menos importante

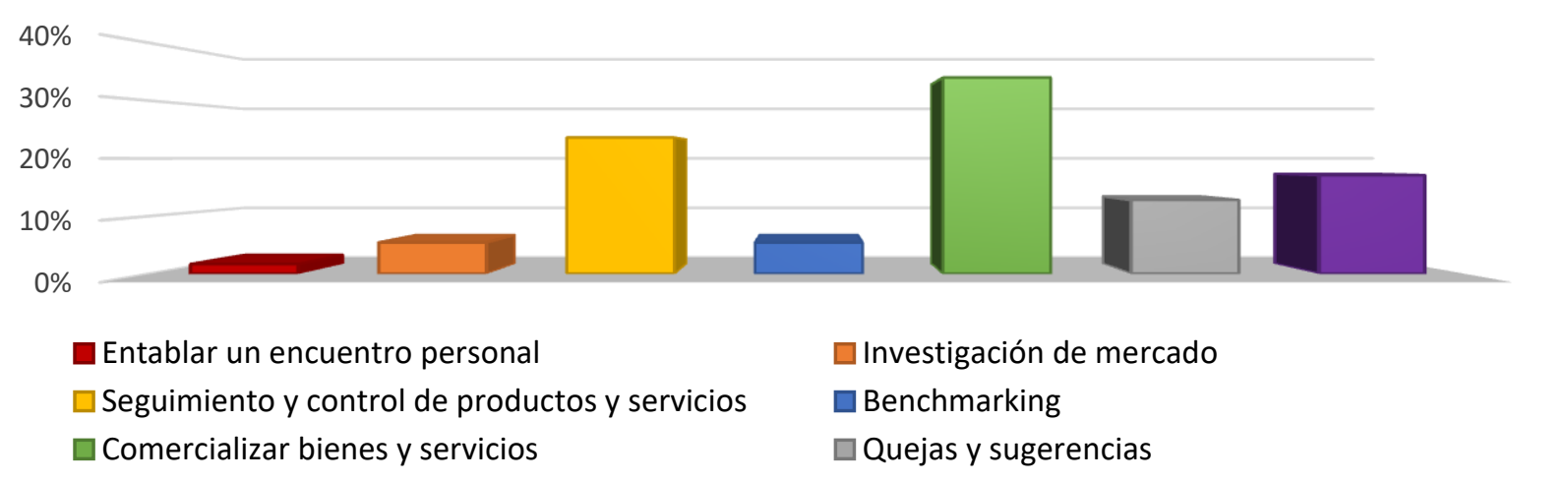

Fuente: Elaboración propia

\section{Pregunta 3}

El mayor uso que se le da a las campañas de telemercadeo en el sector bancario es en la venta y promoción de productos financieros.

Tabla Número 2: Respuestas Expertos

\begin{tabular}{|l|c|c|}
\hline Muy de acuerdo & 7 & $35 \%$ \\
\hline De acuerdo & 10 & $50 \%$ \\
\hline Ni de acuerdo ni en desacuerdo & 3 & $15 \%$ \\
\hline En desacuerdo & 0 & $0 \%$ \\
\hline
\end{tabular}


Gráfica 5 de respuestas pregunta 3.

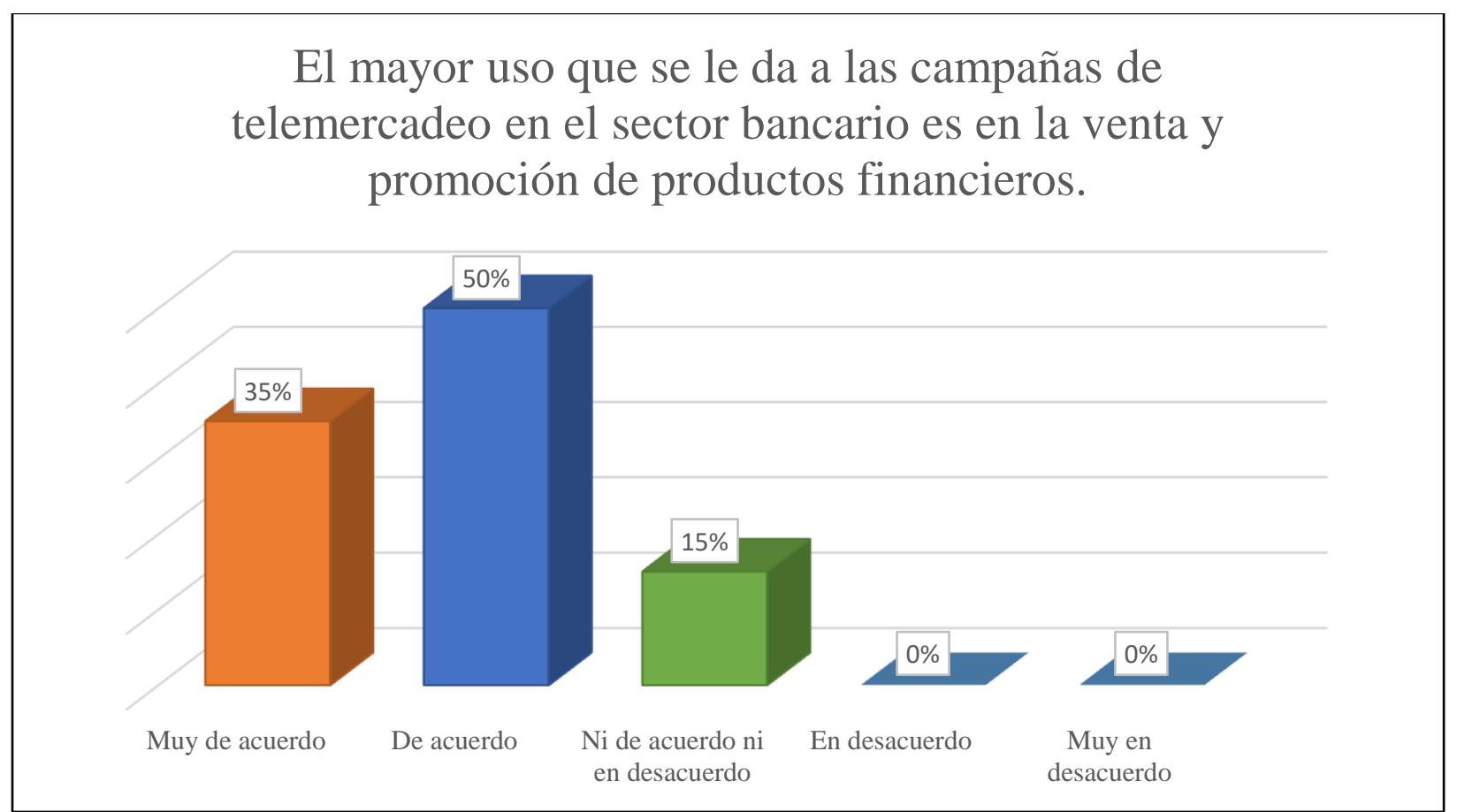

Fuente: Elaboración propia

\section{Pregunta 4}

\begin{tabular}{|lcc|}
\hline Muy de acuerdo & 0 & $0 \%$ \\
\hline De acuerdo & 1 & $5 \%$ \\
\hline Ni de acuerdo ni en desacuerdo & 3 & $15 \%$ \\
\hline
\end{tabular}




\begin{tabular}{|c|c|c|}
\hline En desacuerdo & 10 & $50 \%$ \\
\hline Muy en acuerdo & 6 & $30 \%$ \\
\hline
\end{tabular}

rían el uso de una campaña de telemercadeo, que el uso de una fuerza comercial.

Tabla Número 3: Respuestas Expertos

Gráfico 6 de respuestas pregunta 4

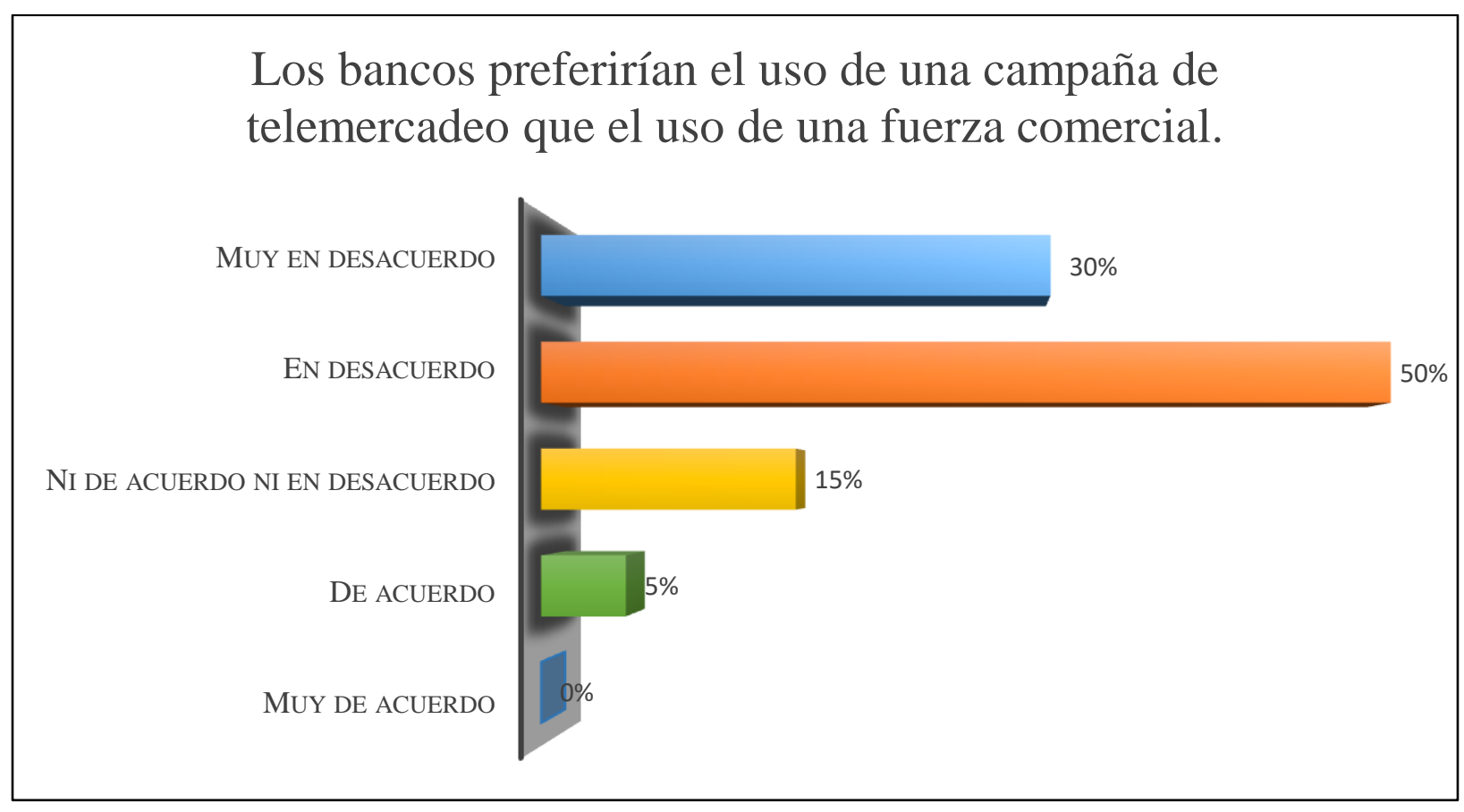

Fuente: Elaboración propia 


\section{Pregunta 5}

Las entidades financieras ofrecen sus productos principalmente por medio de campañas de telemercadeo.

Tabla Número 4: Respuestas Expertos

\begin{tabular}{|ccc|}
\hline Muy de acuerdo & 1 & $5 \%$ \\
\hline De acuerdo & 5 & $25 \%$ \\
\hline Ni de acuerdo ni en desacuerdo & 10 & $50 \%$ \\
\hline En desacuerdo & 4 & $20 \%$ \\
\hline Muy en desacuerdo & 0 & $0 \%$ \\
\hline
\end{tabular}

Gráfico 7 de respuestas pregunta 5

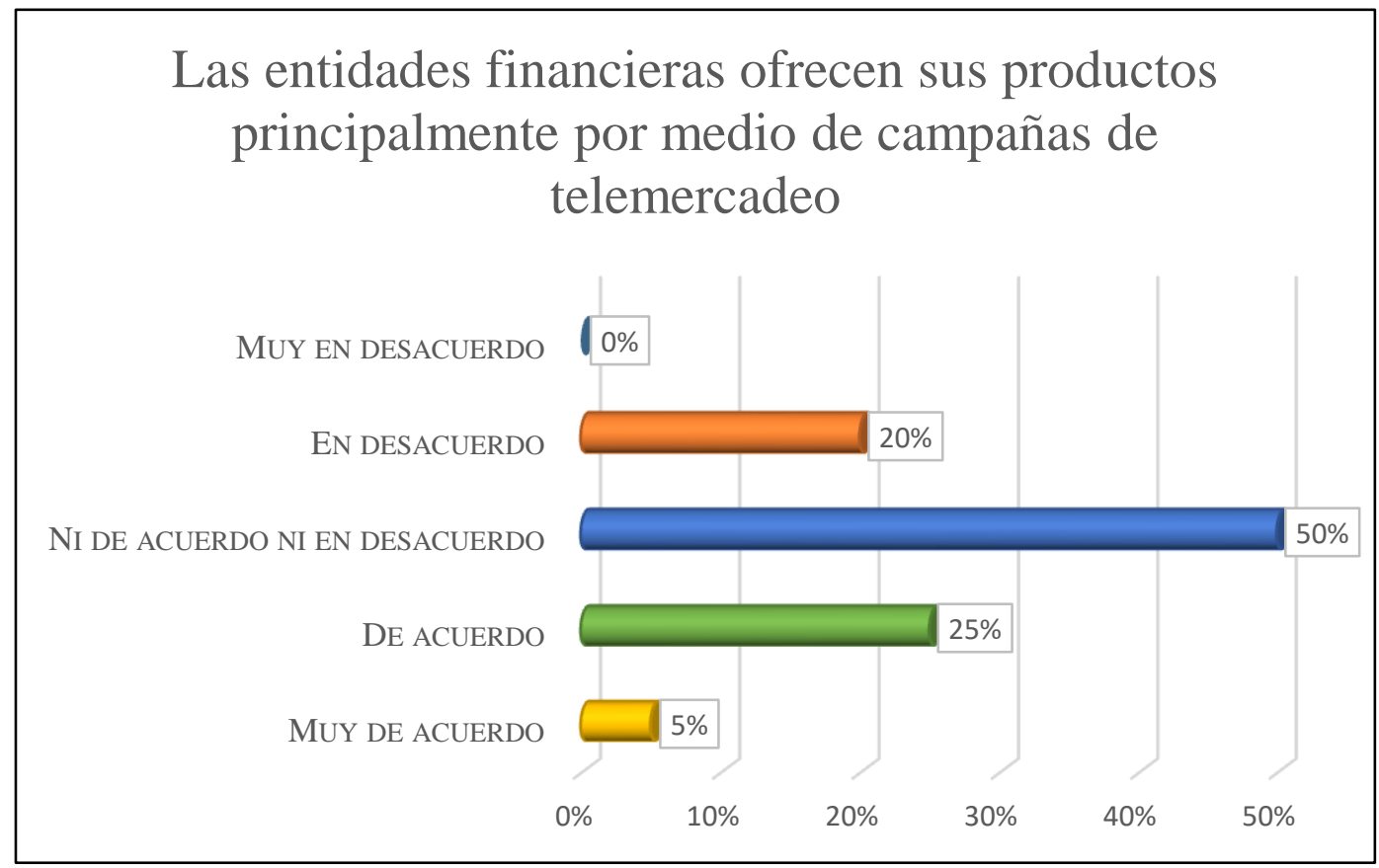

Fuente: Elaboración propia 


\section{Pregunta 6}

Además del telemercadeo, ¿cuál de las siguientes opciones considera más efectivo para el ofrecimiento de productos financieros?

Tabla Número 5: Respuestas Expertos

\begin{tabular}{|lcr|}
\hline & & \\
\hline Mailing & 2 & $10 \%$ \\
\hline Mensajes de texto & 1 & $5 \%$ \\
\hline Atentación en oficina & 8 & $40 \%$ \\
\hline Portal del Banco & 4 & $20 \%$ \\
\hline Publicidad por páginas Web & 4 & $20 \%$ \\
\hline Volantes & 4 & $5 \%$ \\
\hline
\end{tabular}

Gráfico 8 de respuestas pregunta 6

Además del telemercadeo, ¿cuál de las siguientes opciones considera más efectivo para el ofrecimiento de productos financieros?

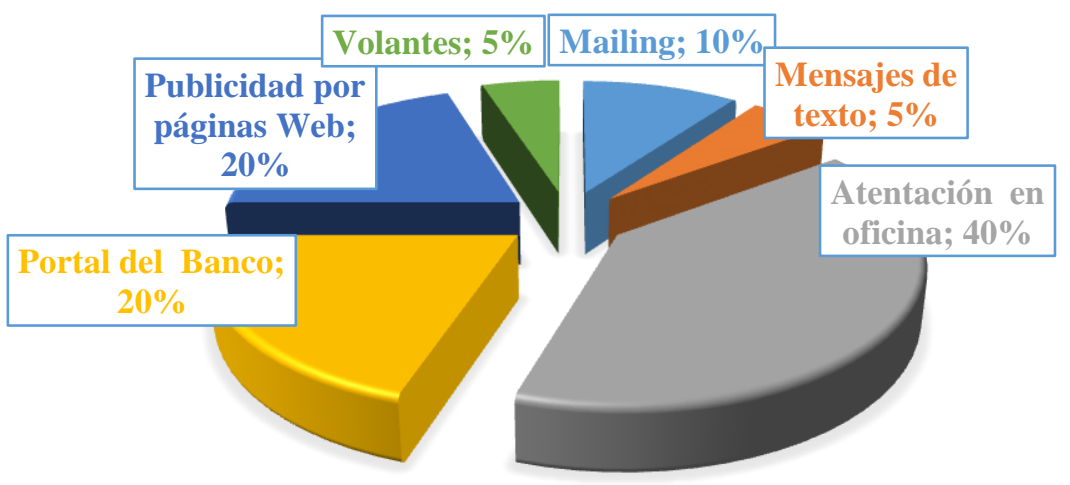

Fuente: Elaboración propia 


\section{Pregunta 7}

De las siguientes opciones, ¿cuál considera usted que es el factor más relevante por el cual es preferible usar el telemercadeo?, siendo 1 las más importante y 7 la menos importante

Tabla Número 6: Respuestas Expertos

\begin{tabular}{|c|c|c|c|c|c|c|c|c|c|}
\hline & 1 & 2 & 3 & 4 & 5 & 6 & 7 & & \\
\hline Bajos costos de ejecución. & 0 & 18 & 25 & 24 & 21 & 18 & 9 & 115 & $21 \%$ \\
\hline Poco desplazamiento de personal. & 42 & 24 & 25 & 12 & 6 & 0 & 0 & 109 & $19 \%$ \\
\hline Efectividad de la campaña. & 0 & 0 & 0 & 4 & 3 & 6 & 4 & 17 & $3 \%$ \\
\hline Acercamiento con el cliente. & 42 & 24 & 15 & 20 & 6 & 0 & 0 & 107 & $19 \%$ \\
\hline $\begin{array}{l}\text { Flexibilidad de la oferta de } \\
\text { productos. }\end{array}$ & 0 & 0 & 0 & 12 & 15 & 10 & 6 & 43 & $8 \%$ \\
\hline Acercamiento directo con el cliente. & 56 & 54 & 35 & 8 & 3 & 2 & 0 & 158 & $28 \%$ \\
\hline Mejoramiento del nivel de servicio. & 0 & 0 & 0 & 0 & 6 & 4 & 1 & 11 & $2 \%$ \\
\hline
\end{tabular}

\section{Gráfico 9 de respuestas pregunta 7}

De las siguientes opciones, ¿cúal considera usted que es el factor más relevante por el cual es preferible usar el telemercadeo?, siendo 1 las más importante y 7 la menos importante

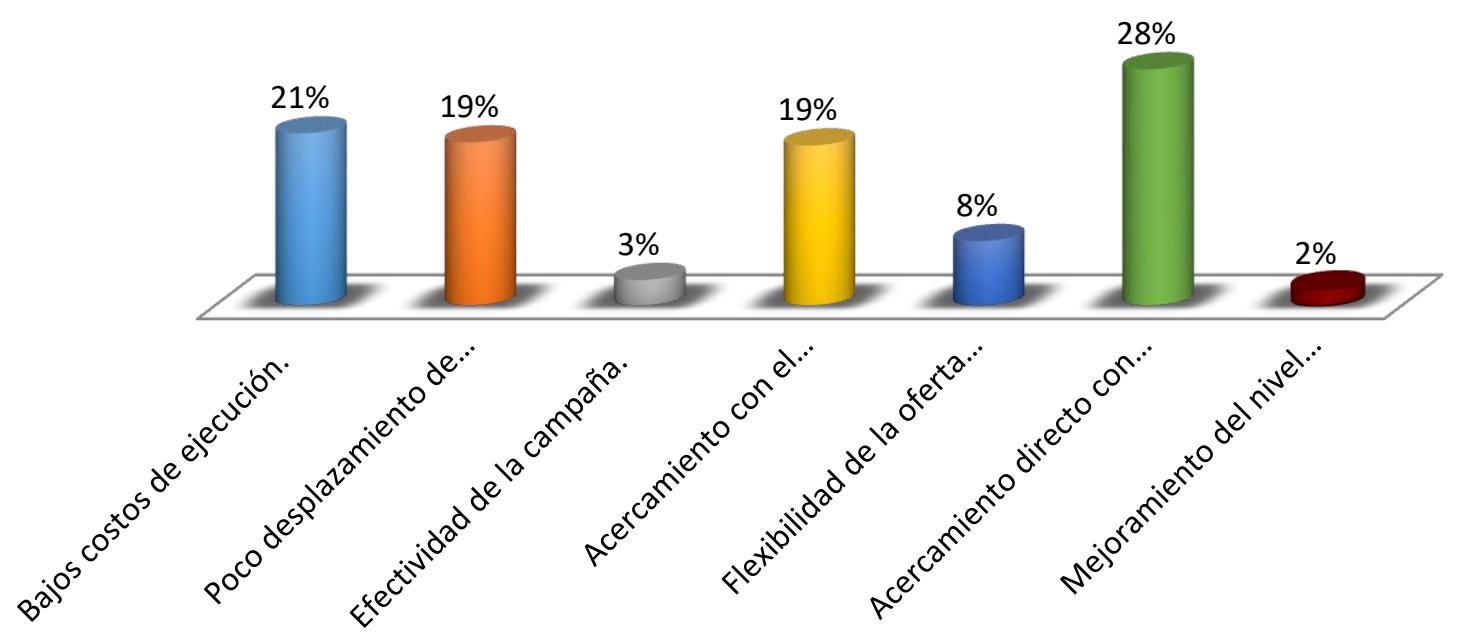

Fuente: Elaboración propia 


\section{Pregunta 8}

Es necesario acoplar el guion de telemercadeo según cada tipo de cliente para poder tener un mayor acierto en la llamada.

\section{Tabla Número 7: Respuestas Expertos}

\begin{tabular}{|c|c|c|}
\hline Muy de acuerdo & 6 & $30 \%$ \\
\hline De acuerdo & 10 & $50 \%$ \\
\hline Ni de acuerdo ni en desacuerdo & 4 & $20 \%$ \\
\hline En desacuerdo & 0 & $0 \%$ \\
\hline Muy en desacuerdo & 0 & $0 \%$ \\
\hline & 20 & \\
\hline
\end{tabular}

\section{Gráfico 10 de respuestas pregunta 8}

\section{Es necesario acoplar el guion de telemercadeo} según cada tipo de cliente para poder tener un mayor acierto en la llamada

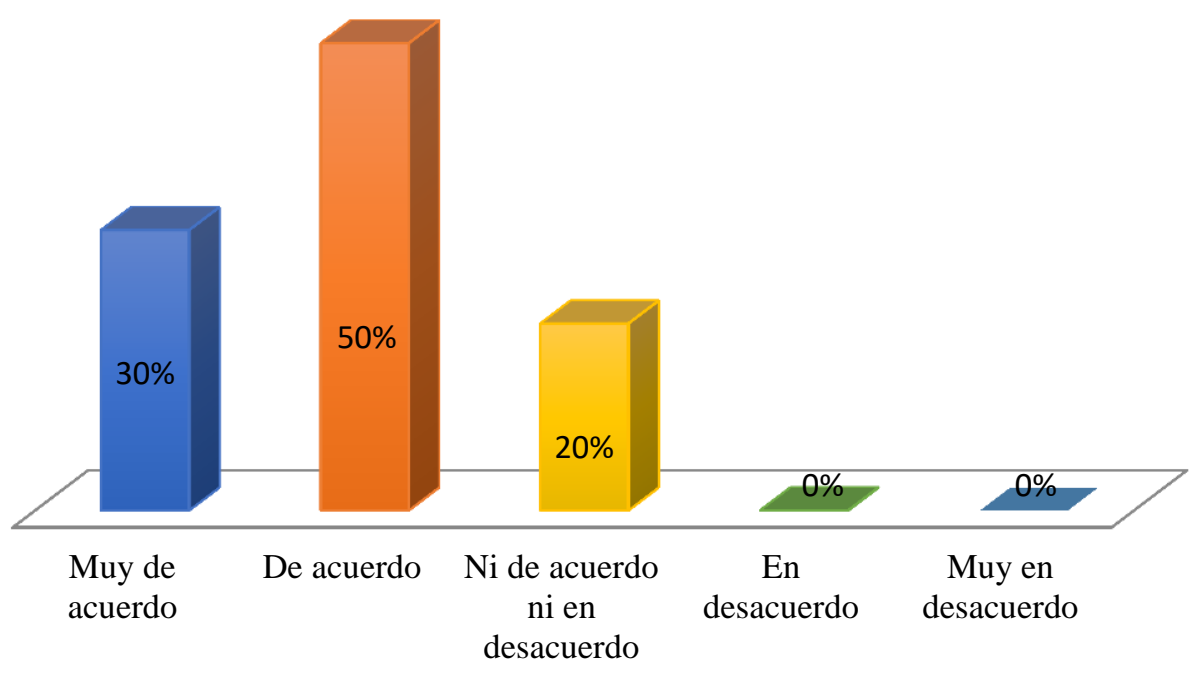

Fuente: Elaboración propia 


\section{Pregunta 9}

La distancia y el contacto no físico se considera que es una desventaja para lograr una campaña de telemercadeo.

Tabla Número 8: Respuestas Expertos

\begin{tabular}{|lcr|}
\hline Totalmente de acuerdo & 4 & $20 \%$ \\
\hline De acuerdo & 5 & $25 \%$ \\
\hline Neutral & 7 & $35 \%$ \\
\hline En desacuerdo & 2 & $10 \%$ \\
\hline Totalmente desacuerdo & 2 & $10 \%$ \\
\hline & 20 & \\
\hline
\end{tabular}

Gráfico 11 de respuestas pregunta 9

La distancia y el contacto no físico se considera que es una desventaja para lograr una campaña de telemercadeo

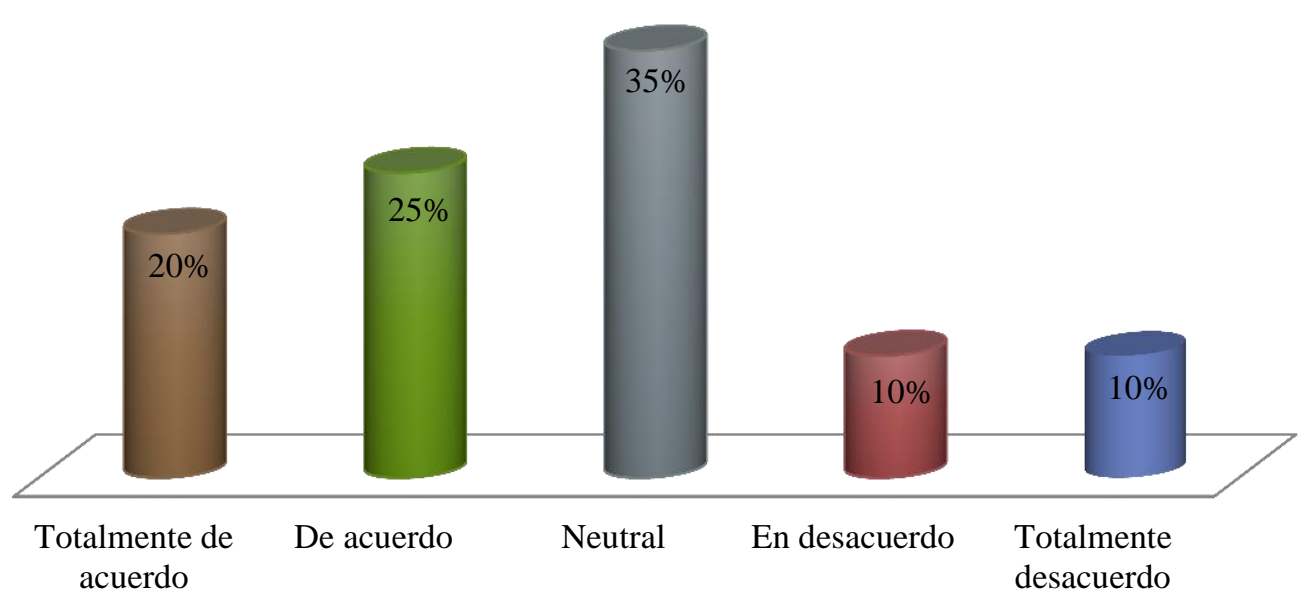

Fuente: Elaboración propia 


\section{Pregunta 10}

Una de las principales ventajas del telemercadeo es la creación de prospectos y mantenimiento de clientes actuales.

Tabla Número 9: Respuestas Expertos

\begin{tabular}{|l|r|r|}
\hline Muy de acuerdo & 7 & $35 \%$ \\
\hline De acuerdo & 5 & $25 \%$ \\
\hline Ni de acuerdo ni en desacuerdo & 4 & $20 \%$ \\
\hline En desacuerdo & 3 & $15 \%$ \\
\hline Muy en desacuerdo & 1 & $5 \%$ \\
\hline & 20 & \\
\hline
\end{tabular}

Gráfico 12 de respuestas de la pregunta 10.

Una de las principales ventajas del telemercadeo es la creación de prospectos y mantenimiento de clientes actuales

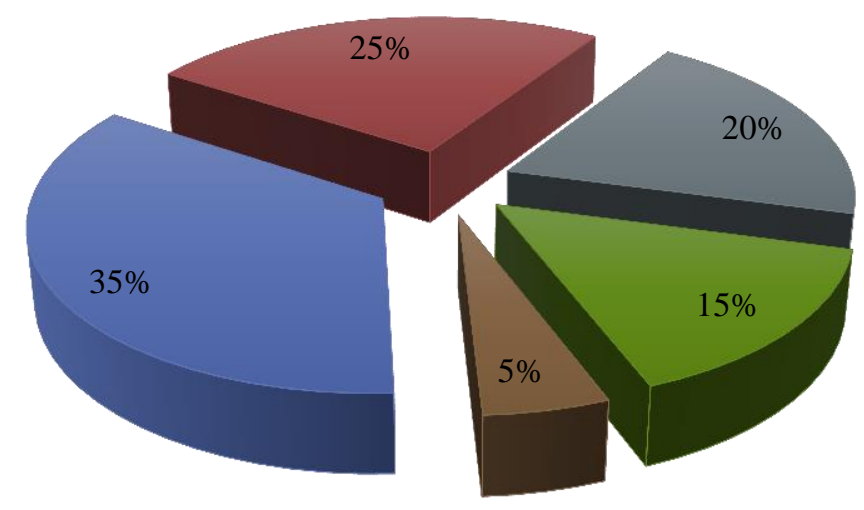

$\square$ Muy de acuerdo

- De acuerdo

Ni de acuerdo ni en desacuerdo

$\square$ En desacuerdo

Muy en desacuerdo

Fuente: Elaboración propia 


\section{Análisis general de resultados obtenidos}

En la pregunta número 1, se le dio una encuesta con una serie de definiciones con respecto a una campaña de telemercadeo, en donde este tenía que ponderar a su disposición la que considerada más importante, con ello la definición predilecta por un $34 \%$ de favorabilidad por parte de los entrevistados, fue aquella que mencionaba que el telemercadeo sirve como medio directo para tener un contacto directo con el cliente, una definición acorde a la investigación realizada en este trabajo. Para la pregunta número 2 también se le dio al entrevistado una serie de opciones para que las ponderara, en esta ocasión con respecto a los usos que tiene el telemercadeo, las opciones $\mathrm{C}$ y $\mathrm{E}$ fueron las de mayor preferencia, que refieren a la comercialización y seguimiento de bienes y servicios, pero por otro lado la opción A, que era la de entablar una cita con algún cliente se mostró como la más baja junto al benchmarking, lo que indica que estas opciones son de muy poco uso o es simplemente nulo.

Con la pregunta número 3 el raciocinio de la pregunta cambia, en donde el entrevistado escoge solo una opción de una afirmación dada, para esta pregunta el 50\% de los entrevistados está de acuerdo con que las campañas de telemercadeo sirven para la venta y promoción de productos financieros, a pesar de esto, el resultado se puede ver sesgado debido a que el preludio de este trabajo es enfocado al sector bancario; para la pregunta 4 se pone en consideración una premisa expuesta, y es la de del telemercadeo como reemplazo de la fuerza comercial, factor que fue negado rotundamente por los entrevistados, y se puede considerar que ambas fuerzas sirven como complemento para sus operaciones, y no como reemplazo de la otra, la siguiente pregunta comprendía el argumento de que los productos principalmente se realizan por medio de campañas de telemercadeo, en donde las opiniones estuvieron divididas pero el factor predominante fue un punto medio, es decir las campañas de telemercadeo sirven como 
herramienta para el ofrecimiento de productos pero no es el método principal o único para hacerle llegar el producto al cliente, dado esto la pregunta 6 se enfoca en poner a consideración del entrevistado, qué otras opciones existen para la promoción de productos, dentro las opciones, la atención en oficina aún es la forma más predominante para tener conocimiento de un producto, pero los portales bancarios, están teniendo más fuerza, junto con la publicidad en otras páginas web, todo debido al fácil acceso a plataformas de internet en cualquier momento y lugar,

La pregunta 8 se refiere más a un factor inherente de la llamada telefónica que se realiza para tener contacto con el cliente, y es el uso del guion, en donde se acierta en que el guion como parte fundamental, si se puede acoplar de la manera más acertada dependiendo del cliente, teniendo en cuenta las limitaciones que existen por perfil del cliente o por características del producto, si se pudiera hacer esto, sería más sencillo realizar un acople con el cliente. En la pregunta 9 se pone a consideración si la distancia y el contacto físico es una desventaja, el 35\% de los entrevistados mostraron una posición neutral, lo que da a entender que el público objetivo de una campaña esta descentralizado, pueden existir clientes que prefieren saber quién les está ofreciendo un producto, pero por otro lado existen aquellos que aprovechan el beneficio de adquirir un producto sin realizar un proceso más complicado. Para finalizar la pregunta 10, una ventaja del telemercadeo, y en la cual la mayoría de entrevistados estuvieron de acuerdo, es que el telemercadeo sirve como herramienta, no solo para la creación de prospectos, es decir futuros clientes, sino también como herramienta para mantener a los clientes actuales. 


\section{Conclusiones}

Las campañas de telemercadeo, como se pudo evidenciar tanto en la investigación como en la recolección de información por parte de los resultados obtenidos por el cuestionario realizado, muestran que el telemercadeo es una herramienta importante, en este caso para una organización de tipo bancario, porque son entidades que tienen en su poder una gran cantidad de clientes, que necesitan de mantenimiento constante para retenerlos, ofreciéndoles beneficios atractivos, pero también es cierto que las herramientas de comunicación deben ir mejorando constantemente, para que estas sean más prácticas en su uso tanto para la organización como para las personas, no solo por términos económicos, sino también por términos de conveniencia de ambas partes.

Si bien, las campañas de telemercadeo funcionan debido al fácil contacto con las personas en razón al gran auge de telefonía móvil en Colombia, ya no es suficiente con ejecutar una llamada esperando resultados positivos, disponiendo de otras herramientas de telecomunicación que también se pueden llegar a utilizar en la ejecución de campañas de telemercadeo y que cada vez se acoplan más a las necesidades de los clientes, lo que como definitiva tiende a lograr una mejor captación de clientes por la flexibilidad de comunicación entre las organizaciones y las personas.

Ya no basta con ofrecer un producto o servicio aquella persona que posiblemente no lo requiera, por el contrario, se deben fomentar mecanismos que hagan llegar información a aquella que si lo requiera y sea de su utilidad, se podría plantear incluso realizar una mezcla de el telemercadeo con otros medios de comunicación que en la actualidad cuentan con innovadora tecnología para acertar las necesidades de las personas, es claro que el telemercadeo es una 
opción para que el cliente pueda interactuar con la organización y de esta manera la conozca en general, en términos de conocer lo que esta ofrece y que pueda incentivarlo a requerir de un producto o servicio que cumpla con sus expectativas.

\section{Recomendaciones.}

Para llevar a cabo mejoras considerables dentro de las campañas de telemercadeo, se recomienda la implementación de sistemas de información que faciliten la actualización de la información de los clientes, para ser más asertivos en sus necesidades, y así consolidar la adecuada recopilación de la información se puede materializar por medio de los siguientes dos métodos.

El primero, consiste en realizar no más de 2 de preguntas antes de culminar la llamada, específicamente preguntas puntuales y cerradas que permitan determinar, formular y perfilar a cada cliente, para mantener actualizado el sistema de CRM, dado que con la información recolectada se podría elaborar y mejorar los productos a partir de las necesidades de los clientes.

La segunda es la implementación de una herramienta informática que se encuentre en las plataformas propias de las entidades financieras, que permita a los clientes colocar información personal adicional, en torno a sus gustos, preferencias y necesidades. A través de esta herramienta se lograra elaborar un perfil más acertado de los clientes y permitirá formular, segmentar y mejorar, los productos y servicios a partir de la caracterización de grupos de clientes. 
De igual forma es importante hacer buen uso del vocabulario, es decir usar palabras y expresiones que faciliten la comunicación con las personas, haciendo uso de palabras sencillas y cómodas de entender, que a su vez promuevan a que se logre el objeto de cada llamada.

Otro elemento que es recomendable, es hacer uso adecuado de las herramientas informáticas que propicien el seguimiento de los clientes potenciales, programando fechas y horas adecuadas en los que las personas se sientan más cómodos para recibir la información del producto o servicio, evitando desperdiciar el tiempo del cliente e interrumpir en momentos inoportunos, lo que a su vez se convierte en una actividad desgastante del Call center.

Además, es de suma importancia tomar en cuenta las objeciones y preguntas del cliente, dado que si un cliente realiza preguntas por el producto o por el servicio, de seguro se logró captar la atención y está interesado, o posiblemente está pensando en otro y prefiera preguntar y escuchar sobre el que si le interesa y que posiblemente no se le está ofreciendo.

También se considera importante que las personas preferiblemente siempre sean atendidas por la misma persona con la que inicia el contacto, ya sea por comodidad del cliente o por la información que este pudo haber proporcionado, y que de igual forma conforta a las personas al crear un vínculo confianza con el mismo.

En cuanto a elementos secundarios, consideramos que el seguimiento que se debe realizar a las personas por los productos adquiridos, es pertinente que se realice una retroalimentación que busque conocer la opinión, quejas y/o sugerencias del ya cliente, para poder mejorar lo ofrecido y poder actuar ante las deficiencias o inconformidades que pueda haber.

También en cuanto al guion, se debe establecer una segmentación de las personas por grupos, de manera que la elaboración del guion vaya conforme de los diversos perfiles que se 
pueden caracterizar dentro de la sociedad, buscando que este trato sea ameno y permita el acercamiento con las personas perfiladas, facilitando la promoción de un producto o servicio.

\section{Referencias}

Corporación Financiera Internacional . (08 de 02 de 2009). Guía informativa de banca PYME. Obtenido de Corporación Financiera Internacional : http://siteresources.worldbank.org/EXTFINANCIALSECTOR/Resources/2828841279136526582/FINAL_SPANISH.pdf

A.M.A. (2017). American Marketing Association. Obtenido de American Marketing Association: https://www.ama.org/resources/Pages/Dictionary.aspx?dLetter=C

A.M.A. (2017). American Marketing Association. Obtenido de A.M.A: https://www.ama.org/resources/Pages/Dictionary.aspx?dLetter=S

A.M.A. (2017). Asociacion Americana de Marketing . Obtenido de A.M.A: https://www.ama.org/resources/Pages/Dictionary.aspx?dLetter=P

Álvarez Sánchez , J. (2007). Telemarketing. La red como soporte de marketing y comunicación. Vigo: Ideaspropias. Recuperado el Mayo de 2016, de https://books.google.es/books?hl=es\&lr=\&id=w7QkCnf8HIgC\&oi=fnd\&pg=PA1\&dq=q ue+es+telemercadeo\&ots=2GfjSZBmtQ\&sig=nnX4QQDUDmJrqIrYAIswZo4sxAg\#v=o nepage\&q\&f=false

Banc.Oportunidades. (2015). Reporte de inclucion financiera. Bogota: Banco de Oportunidades.

Cava, L. G. (2004). CRM: Tres estrategias de éxito. Barcelona: Estudio del eb center.

DANE. (2015). La población proyectada de Colombia. Bogota : Departamento Administrativo Nacional de Estadística .

Diccionario de Enciclopédico Océano. (1997). Diccionario de Enciclopédico Océano. Edición 1997. 
Genesys. (2008). Estrategias de servicio al cliente para el sector de banca minorista. Genesys. America Latina: Genesys.

Groundwater. (2005).

Hernández Sampieri, R., Fernández Collado, C., \& Baptista Lucio, M. (2014). Metodología de la investigación. Mexico: McGraw - Hill / Interamericana Editores S.A. Recuperado el 2017, de http://upla.edu.pe/portal/wp-content/uploads/2017/01/Hern\%C3\%A1ndez-R.2014-Metodologia-de-la-Investigacion.pdf.pdf

Javeriana, P. U. (12 de 11 de 2008). Plan de negocios para crear una empresa de servicios de CRM. Bogota, Colombia.

Kazañetz, G. (Marzo de 2004). Importancia del Telemercadeo en las Organizaciones. Obtenido de Universidad Abierta Interamericana: http://imgbiblio.vaneduc.edu.ar/fulltext/files/TC048653.pdf

Klaric, J. (2012). Estamos ciegos. Perú: Planeta.

Likert, R. (1932). Estados Unidos.

McCarthy, M., \& O’Donnell, J. (2002). FTC Idea Could Get Telemarketers to Stop Calling. USA.

Ministerio de Comercio, I. y. (12 de 08 de 2014). Decreto 1499 del 12 de Agosto de 2014. Bogota, Colombia, Colombia: Republica de Colombia.

Morris, E., Ancajima, A., Galindo, C. C., Guido, C., \& Mejía, E. (2009). Servicios de contact center basados en offshore outsourcing. Lima-Perú: Universidad ESAN.

Muñiz, R. (2005). Una llamada ganadora. Emprendedores, 000-006.

Pereira, J. E. (2005). El marketing a tu alcance. Revista Digital MERCADEO.COM, http://www.mercadeo.com/blog/2010/01/antecedentes-del-telemarketing/.

Prieto, R. D. (2008). Introducción al sistema financiero y bancario. Bogotá D.C : Politécnico Grancolombiano Institución Universitaria Member of Whitney. 
Prime Contact Center Solutions S.A. (8 de 05 de 2012). Glosario de call y contact center. Obtenido de Prime Contact Center Solutions : http://www.primeccs.com/images/stories/archivos/glosario\%20de\%20call\%20y\%20conta ct\%20center\%20(art).pdf

Sánchez, D., Lis, J., \& Herrera, J. P. (2012). Estudio del Sector Telecomunicaciones en Colombia. Bogota: Grupo de Estudios Económicos.

(2007). Análisis de una campaña. La eficacia del telemarketing , a examen. En A. P. Seijo, $M K$ Marketing+Ventas (págs. 38-45). Barcelona: banca minorista.

Semana. (27 de 06 de 2015). Colombia, el país de los 'smartphones'. Revista Semana, págs. http://www.semana.com/tecnologia/articulo/colombia-el-pais-de-los-

smartphones/432806-3. Obtenido de http://www.semana.com/tecnologia/articulo/colombia-el-pais-de-lossmartphones/432806-3

Stanton, W. J., Etzel , M. J., \& Walker, B. J. (2007). Fundamentos de Marketing. Mexico: The McGraw-Hill.

Stringer. (1999). Metdodologia de la investigacion. Mexico DF: Mc Graw Hill.

Tang, H. (2014). A COMPARISON OF TWO MODELING TECHNIQUES IN CUSTOMER TARGETING FORBANK TELEMARKETING. Georgia State University, 1-49.

Thirion, J. M. (10 de 02 de 2010). Los Call Center y nuevos trabajos del siglo XXI Marketing Directo. págs. 1-2.

TIC, M. (2014). Estudio de Telecomunicaciones en Colombia. Bogota: MinTIC.

U.Autónoma, D. O. (2013). Creación de campaña de sensibilización al programa plan padrino de fundamor, para la vinculación de nuevos padrinos. Santiago de Cali.

U.Javeriana. (12 de 11 de 2008). Plan de negocios para crear una empresa de servicios de CRM. Bogota, Colombia. 
Vaca Zambrano, M. G., \& Corella Parra, C. R. (2008). Recuperado el 2017, de http://dspace.udla.edu.ec/bitstream/33000/2139/1/UDLA-EC-TTM-2008-02.pdf

Villa, P. (2007). Estudio del Telemercadeo en el mundo. Madrid: INFOADEX,S.A.

Weber, M. ((1864-1920)). Metodologia de la Investigacion. Mexico DF: McGRAW-HILL. 
Cuestionario de Impacto de las campañas de telemercadeo en el sector bancario.

\begin{tabular}{l}
\hline UNIVERSIDAD SANTO TOMAS \\
\hline FACULTAD DE ADMINISTRACIÓN DE EMPRESAS \\
Formato de cuestionario sobre el impacto de las campañas de tele \\
mercadeo de ventas en el sector bancario. \\
Fecha: \\
Nombre encuestado: \\
Nombre del encuestador:
\end{tabular}

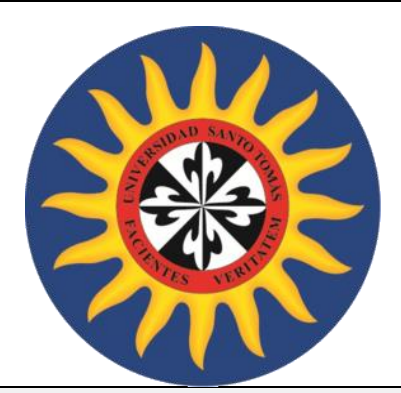

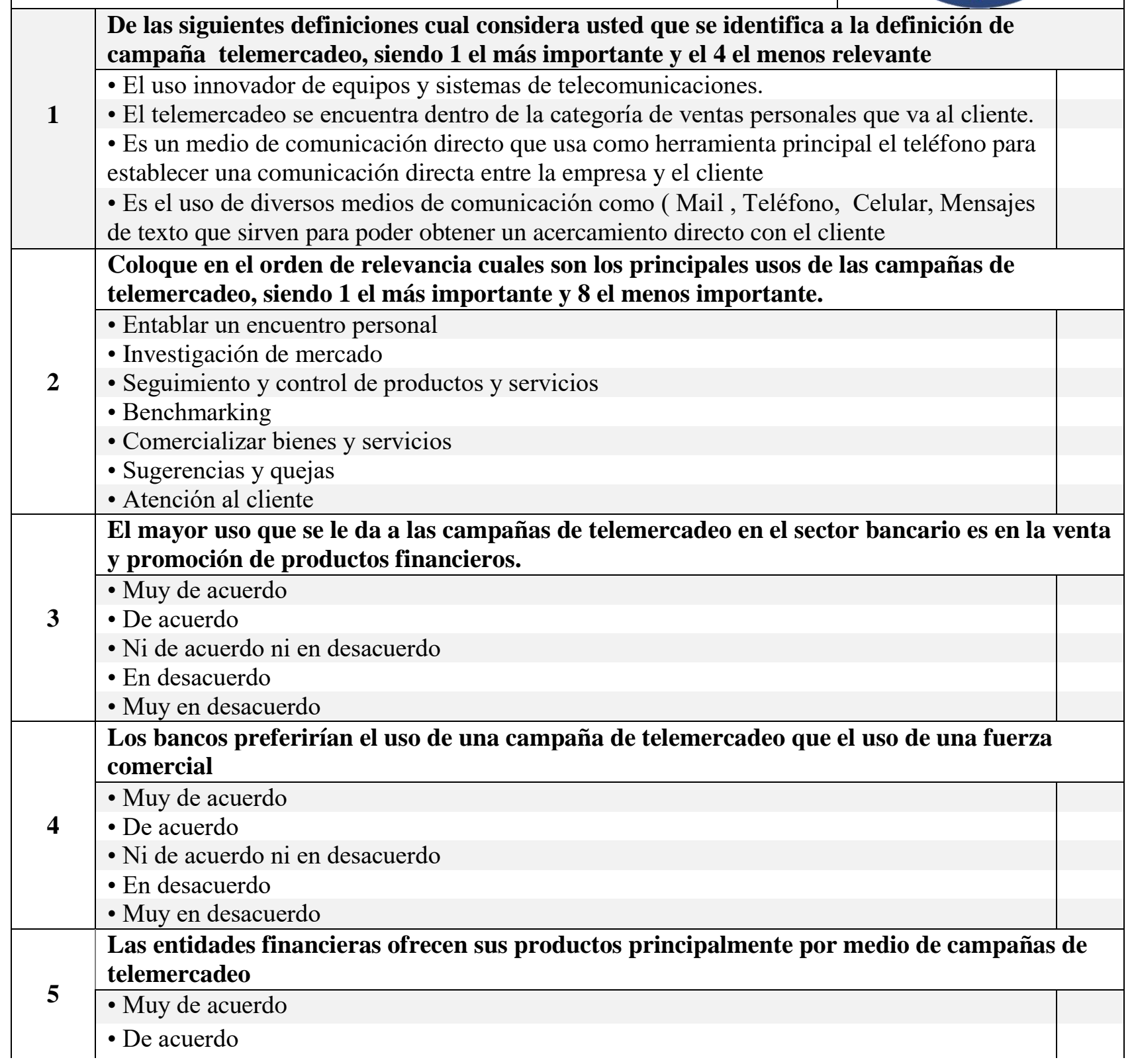


- Ni de acuerdo ni en desacuerdo

- En desacuerdo

- Muy en desacuerdo

¿Qué otros medios considera más efectivos para la recepción de productos financieros considera más efectivos?

- Mailing

- Mensajes de texto

- Atentación en oficina

- Portal del Banco

- Publicidad por páginas Web

- Volantes

De las siguientes opciones cual considera usted que es el factor más relevante por el cual es preferible usar el telemercadeo, siendo 1 las más importante y 7 la menos importante

- Bajos costos de ejecución.

- Poco desplazamiento de personal.

$7 \quad$ - Efectividad de la campaña.

- Acercamiento con el cliente.

- Flexibilidad de la oferta de productos.

- Acercamiento directo con el cliente.

- Mejoramiento del nivel de servicio.

Es necesario acoplar el guion de telemercadeo según cada tipo de cliente para poder tener un mayor acierto en la llamada

- Muy de acuerdo

8 - De acuerdo

- Ni de acuerdo ni en desacuerdo

- En desacuerdo

- Muy en desacuerdo

La distancia y el contacto no físico se considera que es una desventaja para lograr una campaña de telemercadeo

- Totalmente de acuerdo

$9 \quad$ En desacuerdo

- Neutral

- En desacuerdo

- Totalmente desacuerdo

Una de las principales ventajas del tele mercadeo es la creación de prospectos y mantenimiento de clientes actuales

10 - Muy de acuerdo

- De acuerdo

- Ni de acuerdo ni en desacuerdo

- En desacuerdo

- Muy en desacuerdo 